\title{
Diacronies i sincronies al jaciment de l'Espina C (Tàrrega, l'Urgell): ocupacions del V, III i II mil·lenni cal ANE
}

\section{Diachrony and synchrony at the site of Espina $C$ (Tàrrega, Urgell): occupations from the 5th, 3rd and 2nd millennium cal $B C$}

\begin{abstract}
Aquest article fa referència a l'estudi del jaciment de l'Espina C i a la vegada focalitza la problemàtica interpretativa d'aquells jaciments arqueològics formats exclusivament per estructures negatives excavades al subsòl. Aquestes generalment es troben disseminades i inconnexes físicament, i proporcionen a l'assentament una estratigrafia horitzontal en la qual totes les estructures se situen en un mateix pla, independentment de la seva cronologia. Aquest tipus de registre es contraposa al dels poblats o coves els quals preserven una estratigrafia vertical que permet la seqüència dels diferents contexts. En el cas de l'Espina C l'estratigrafia horitzontal no és fruit d'una única ocupació humana, sinó de vàries en diferents moments cronològics i separades per llargs períodes de temps. Aquest fet implica l'existència de diferents assentaments distribuits dins d'un mateix espai físic. Tot i que aquesta problemàtica es pot donar en assentaments a l'aire lliure de qualsevol cronologia, aquest treball se centra en els d'època prehistòrica.
\end{abstract}

Paraules clau: prehistòria recent, fosses, estratigrafia horitzontal.
This article refers to the study of the archaeological site of Espina C consisting exclusively of pits dug into the subsoil. The pits are usually dispersed and unconnected, offering the possibility of carrying out a horizontal stratigraphy study as they all, regardless of their chronology, are located in the same plane. This type of site is differs from that of settlements and caves with vertical stratigraphy allowing a sequencing of the different contexts. The horizontal stratigraphy of Espina $\mathrm{C}$ is not the result of a single human occupation, but corresponds to different settlement phases separated by long intervals of time occupying the same space. Although this situation can occur at open air settlements of any chronology, the current paper focuses on the Prehistoric period.

Keywords: Recent Prehistory, pits, horizontal stratigraphy. 


\section{Introducció}

Aquest article aporta novetats importants respecte a la cronologia del jaciment de l'Espina C, amb la identificació de tres ocupacions distanciades en el temps que contrasta amb l'atribució cronològica aportada tant en la Memòria de la intervenció arqueològica lliurada al Departament de Cultura (Piera 2007) com també en la publicació d'un article en la revista Urtx (Piera et al. 2009) en què s'atribuïen totes les estructures, com també les dades econòmiques i tecnològiques, al període del Neolític Final, l'únic que havia estat datat. Fruit d'una nova revisió del material ceràmic $\mathrm{i}$ de la realització de dues noves datacions de radiocarboni s'ha evidenciat la diacronia entre determinades estructures. D'altra banda, també el remuntatge de materials ceràmics recuperats en diferents estructures ha permès definir relacions de sincronia en llurs amortitzacions.

\section{Situació i motius de la intervenció}

El jaciment de l'Espina $C^{1}$ (Tàrrega, l'Urgell) se situa en el bell mig de la plana occidental catalana - la part occidental de la depressió central catalana- al capdamunt d'un turó, el de l'Espina, situat a 1,5 quilòmetres al nord-oest del nucli de Verdú i a 3 quilòmetres al sud del nucli de Tàrrega. Les estructures arqueològiques es localitzaren a l'est del turó, en un punt de bona visibilitat respecte a les planes adjacents ja que es troba lleugerament elevat.

L'adequació d'una finca agrícola l'any 2005, motivà la realització d'una intervenció arqueològica d'urgència al jaciment de l'Espina $C^{2}{ }^{2}$ encaminada a determinar la presència o absència de restes arqueològiques sota el sòl agrícola i d'avaluar-ne l'entitat. Per tal d'assolir aquest objectiu es realitzaren rases de sondeig que permeteren localitzar diverses estructures arqueològiques i que, posteriorment, motivaren l'obertura de tota la finca agrícola en qüestió, mitjançant l'extracció mecànica de la capa vegetal, d'una àrea de $3.500 \mathrm{~m}^{2}$. Tot i que la major part de les estructures arqueològiques aparegueren en el centre de la finca, n'hi havia d'altres situades prop dels límits, fet que podria suggerir que la superfície del jaciment fos més àmplia que l'àrea intervinguda. Posteriorment, l'any 2006, es realitzà l'excavació manual de les estructures localitzades seguint una metodologia de registre arqueològic, basada en la documentació de les unitats estratigràfiques $i$, en determinades estructures, la situació espacial dels materials dins de cada unitat estratigràfica. Els treballs realitzats quedaren reflectits en la corresponent memòria (Piera 2007) i, dos anys després, es publicà un estudi interdisciplinari realitzat en col-laboració amb diversos investigadors que aportà noves dades socioeconòmiques dels grups humans que ocuparen aquest indret (Piera et al. 2009). L'any 2014 en el marc d'un treball de fi de màster es portà a terme l'estudi del material ceràmic i es

1. Les coordenades UTM són: X: 344084 Y: 4609817.

2. Promoguda pel Servei d'Arqueologia i Paleontologia de la Generalitat de Catalunya i realitzada per l'empresa Arqueociència. realitzaren noves datacions radiocarbòniques (Piera 2014). Actualment se segueix portant a terme l'estudi de l'assentament i del seu entorn en el marc d'una tesi doctoral. ${ }^{3}$

\section{Problemàtica}

El jaciment de l'Espina C és un assentament a l'aire lliure format exclusivament d'estructures negatives excavades al subsòl i inconnexes. La principal característica d'aquest tipus d'assentament és la manca de relació estratigràfica entre cadascuna de les estructures que el conformen i la corresponent desconnexió entre els respectius rebliments. Tanmateix, el fet que les estructures sovint apareguin agrupades i ubicades dins d'un determinat marc espacial, més o menys delimitat, ja sigui un turó o una terrassa, proporciona una imatge des d'una perspectiva actual d'un únic conjunt $o$ assentament. Tot i això, ja a fi de segle xx, les excavacions a la Bòbila Madurell (Martín et al. 1988), Hort d'en Grimau (Mestres et al. 1998) o Can Roqueta (González et al. 1999) permeteren detectar una coincidència espacial entre ocupacions cronològicament allunyades. A la vegada, però, és possible identificar agrupacions d'estructures d'un mateix període en unes àrees específiques.

En els darrers anys, l'arqueologia preventiva lligada a projectes urbanístics i d'infraestructures, ha fet augmentar considerablement el nombre d'aquest tipus d'assentaments a l'aire lliure. Aquestes intervencions han permès registrar una gran varietat d'estructures, dinàmiques de rebliment $i$ funcionalitats diferenciades, contribuint significativament en l'avenç del seu coneixement.

Entre les estructures que conformen aquests assentaments, es poden trobar petits forats que han estat interpretats com elements de suport d'una estructura aèria (Equip Minferri 1997), fosses amb ceràmiques senceres que han estat interpretades com a estructures per a sostenir els recipients ceràmics (Carlús, González 2008) o també estructures amb restes de rubefacció que han estat identificades per a la combustió (Fortó et al. 2005). En determinats casos, les grans fosses excavades al subsòl han estat interpretades com a espais de treball a Can Vinyalets II (Font 2006) i al Vapor Gorina (Roig et al. 2008) o també com a espais d'hàbitat, depenent dels elements que s'hi troben associats (Pons 1994; Palomo et al. 2002; Clop et al. 2005; Terrats 2010). Determinades fosses excavades al subsòl, de planta circular i de certa fondària, han estat identificades com a sitges (Mestres et al. 1998; Alonso 1999). Altres amb inhumacions han estat interpretades com a estructures funeràries a l'Hort d'en Grimau (Mestres 1988-1989) o la Serreta (Esteve et al. 2012). Finalment, altres fosses de planta circular però menys profundes que les sitges han estat classificades com a fosses simples o cubetes en base a l'índex "diàmetre de boca/profunditat conservada" i vinculades a l'emmagat-

3. Tesi (en curs): El procés de neolitització a la plana occidental catalana. Dirigida pel Dr. Miquel Molist (UAB) i el Dr. Xavier Clop (UAB). Aprofito per agrair l'ajuda rebuda de tots dos i també del Sr. Josep Gallart (Serveis Territorials de Cultura a Lleida. Generalitat de Catalunya). 


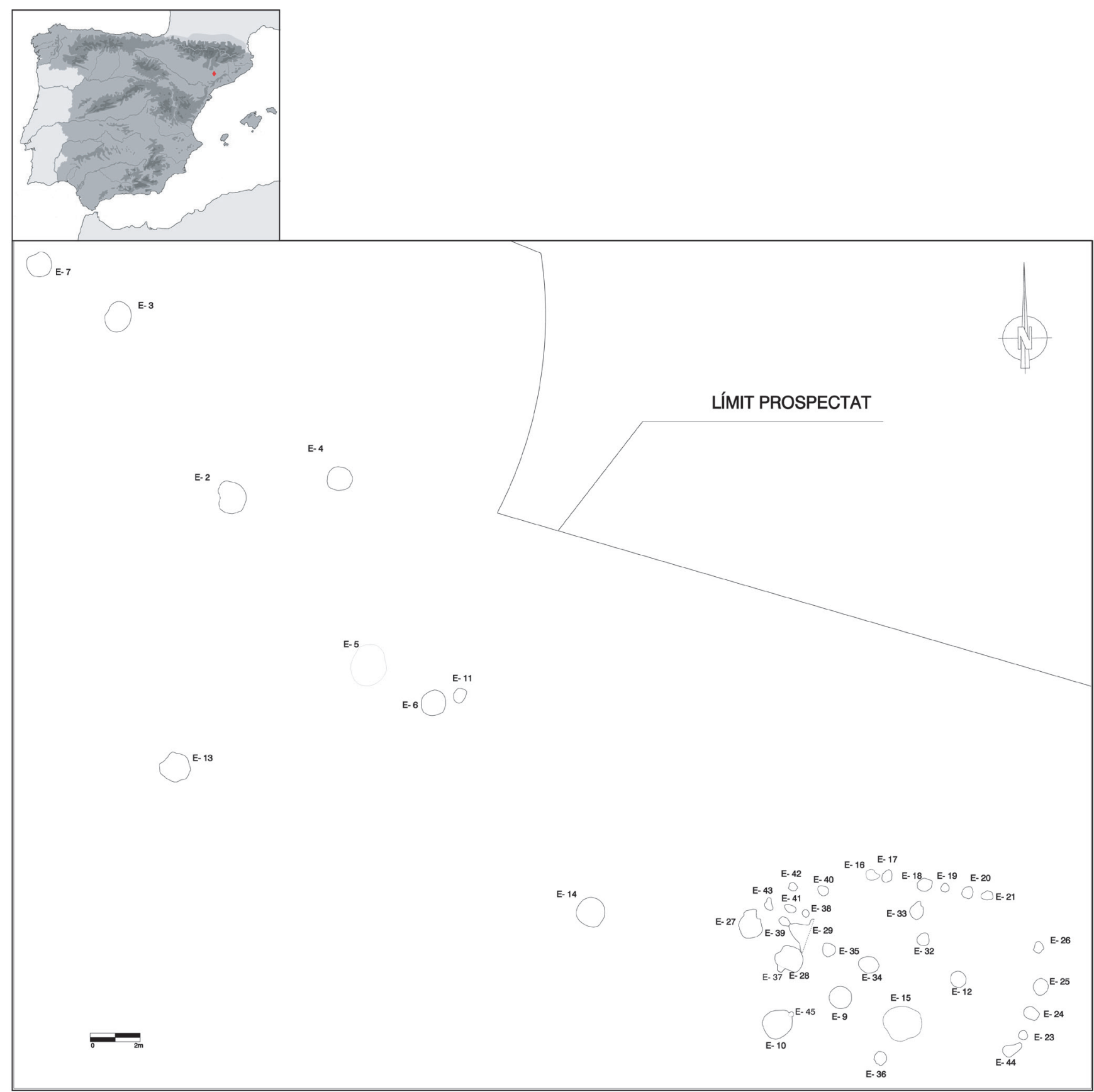

Figura 1. Planta general de l’Espina C.

zematge o altres funcionalitats (Prats 2013). També diversos estudis han contribuït al coneixement d'aquest tipus d'assentament, com l'anàlisi comparativa de les estructures i dels materials arqueològics entre dos assentaments (Bouso et al. 2004) o la recopilació d'un gran nombre de datacions radiocarbòniques a Can Roqueta que manifesten una diacronia de les ocupacions que van del Neolític al bronze i l'edat del ferro (Carlús et al. 2008). Tanmateix, no és un tipus d'assentament exclusiu de l'època prehistòrica, sinó que sovint, entre les ocupacions prehistòriques, també se'n detecten d'històriques, ibèrica a Mas d'en Boixos (Farré et al. 2002) o ibèrica i romana als Llirians del Mas (Piera et al. 2013).

La inexistència de relació física entre estructures i la manca d'una seqüència estratigràfica general dels jaciments, fa que es disposi d'espais independents, difícilment relacionables. De tal manera que una de les principals problemàtiques a resoldre d'aquest tipus de registre arqueològic és la determinació de l'existència o no de vincle entre les diferents estructures. Aquesta problemàtica engloba en ella mateixa dues esferes diferenciades de vincle. Per una banda, dins una esfera temporal àmplia, planteja si el registre arqueològic és fruit d'una o de múltiples ocupacions humanes al llarg del temps. I, per l'altra, una esfera més específica planteja la sincronia i/o diacronia de cadascuna de les estructures arqueològiques vers les altres.

Es tracta, doncs, d'una problemàtica temporal que consisteix en la complexitat de definició dels possibles horitzons cronològics en l'assentament, en què 
l'adscripció cronocultural del material arqueològic i les datacions radiocarbòniques tenen un paper principal. I també relacional, en l'establiment de quina manera les estructures es vinculen entre elles en cadascun d'aquests horitzons. Per a aquesta segona esfera, les relacions estratigràfiques o els remuntatges entre materials arqueològics, de diferents contexts, esdevenen determinants.

Una altra problemàtica, exposada ja per Bellido, és la identificació de la funcionalitat de les estructures que el conformen (Bellido 1996). Sobretot perquè l'alt grau d'arrasament fa que no es conservi la morfologia completa de les estructures, ni tampoc els nivells de circulació dels assentaments. Un altre element a tenir present és que les dimensions dels assentaments poden ser majors que les àrees intervingudes arqueològicament. Aquest fet fa que no sempre es disposi d'una visió completa de tot el conjunt. Per exemple, l'obertura de grans superfícies, en alguns casos, ha propiciat la detecció de grans fossats que encerclen diverses estructures negatives a Mas d'Is, Revilla del Campo, Camino de las Yeseras (Márquez, Jiménez 2010) o Ca l’Estrada (Fortó et al. 2005) a Catalunya. Tanmateix, en el cas de l'Espina C, no se n'hi ha detectat cap.

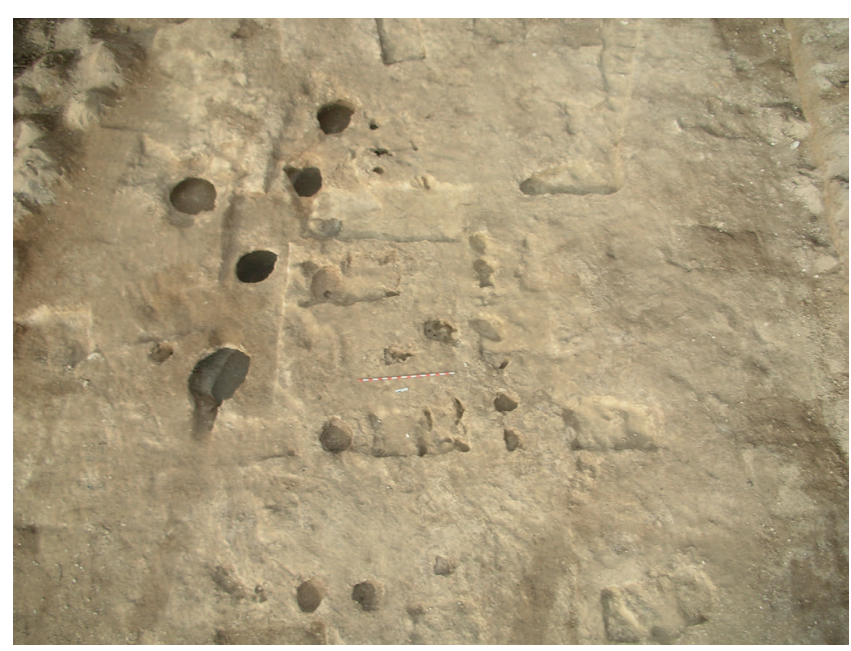

Figura 2. Vista de les estructures de l’Espina C.

\section{Metodologia}

Per abordar la problemàtica sobre com identificar els funcionaments sincrònics i/o diacrònics de les estructures d'aquests assentaments, i a la vegada definir quin ha estat el seu procés de formació, s'ha utilitzat una metodologia que conjuga l'anàlisi de diferents elements del registre, com ara la ubicació espacial de les estructures, la seva morfologia, les relacions estratigràfiques, les dinàmiques de rebliment, els materials arqueològics continguts, l'establiment de cronologies relatives i la datació absoluta de determinats contexts arqueològics.

A partir de l'anàlisi de la ubicació de les estructures dins del jaciment, es detecten patrons de distribució, no aleatoris, que poden indicar l'existència d'un determinat vincle de sincronia entre estructures inconnexes espacialment. Per altra banda, les relacions estratigràfiques observades en el registre arqueològic, com ara la superposició d'estructures, permeten detectar relacions de diacronia. També l'anàlisi de la morfologia, dimensions i dinàmiques de rebliment de les estructures arqueològiques permet distingir similituds entre diferents estructures que podrien ser un indici de l'existència d'una relació de sincronia a contrastar, ja que, òbviament, llur similitud es pot deure a altres causes. La recerca específica de remuntatges, entre el material arqueològic de diferents contexts, pot ajudar a detectar relacions de sincronia entre les estructures inconnexes. També l'anàlisi dels aspectes tecnològics, morfològics i decoratius dels materials arqueològics, i llur comparació amb altres materials procedents de contexts arqueològics datats, pot permetre definir adscripcions cronoculturals i establir relacions de diacronia. Finalment, les datacions radiocarbòniques proporcionen cronologies absolutes, amb intervals de probabilitat, que poden permetre definir relacions de diacronia i/o sincronia entre diferents estructures.

L'objectiu és la seqüenciació dels diferents processos de formació, d'ús i d'amortització de les estructures arqueològiques, i la reconstrucció, al màxim possible, del procés de formació de l'assentament.

\section{Les estructures arqueològiques}

En el jaciment de l'Espina C es localitzen 40 estructures prehistòriques i 71 estructures d'època moderna, totes excavades al subsòl. Entre les modernes trobem 3 rases de vinya, 67 fosses rectangulars $(1 \times 2 \mathrm{~m})$, disposades de manera regular que suggereixen la plantació d'un determinat tipus d'arbre, i una canal de $25 \mathrm{~m}$ de longitud, possiblement vinculada a algun tipus de gestió de l'aigua. Aquesta és formada per dues fileres de pedres, disposades de cantó a cada costat de rasa, i cobertes per lloses planes.

Les estructures prehistòriques es poden classificar en tres grups a partir de la morfologia i les dimensions de la fossa:

1. Fosses de planta circular o lleugerament oval, d'1 $\mathrm{m}$ de diàmetre de boca, de fondàries variables i amb perfils de parets cilíndrics, globulars i troncocònics. Identificats 12 exemplars que han estat interpretats com a sitges. Figura 3.

2. Fosses de planta circular, d'escàs diàmetre de boca, poca fondària i amb un perfil de parets de pendent suau. Localitzats 3 exemplars que han estat identificats com a cubetes. Figura 4.

3. Fosses de petit diàmetre de boca, d'escassa fondària i, majoritàriament, de parets verticals. Identificats 25 exemplars que han estat interpretats com a forats de pal. Figura 5.

La major part de les estructures prehistòriques, incloent tots els forats de pal, més 5 fosses d'emmagatzematge i una cubeta, es troben agrupades a la zona central de l'àrea intervinguda. Les altres estructures es distribueixen de manera més dispersa en direcció nord-oest. Algunes resten completament aïllades de la resta, E-13 i E-14, i d'altres formen agrupacions de dues estructures, E-2 i E-4 i també E-3 i E-7, o de tres estructures, E-5, E-6 i E-11. 


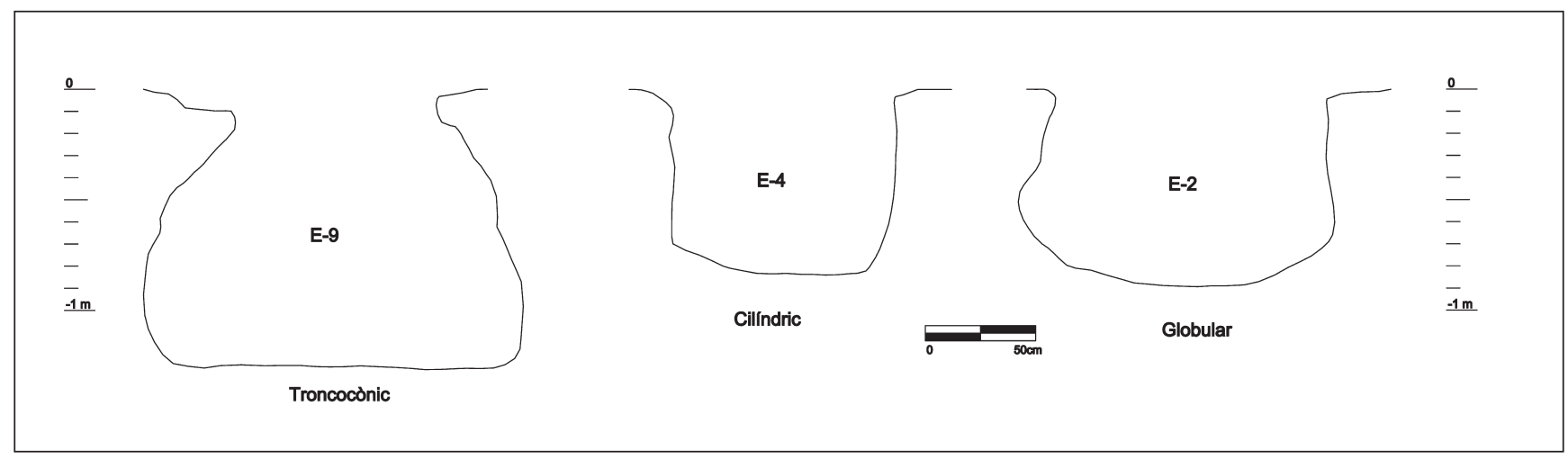

Figura 3. Seccions de les estructures d'emmagatzematge.

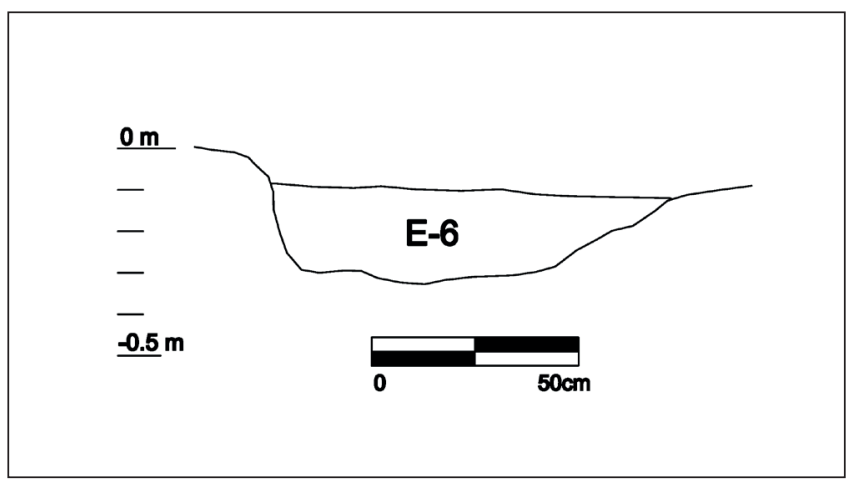

Figura 4. Secció d'una cubeta.

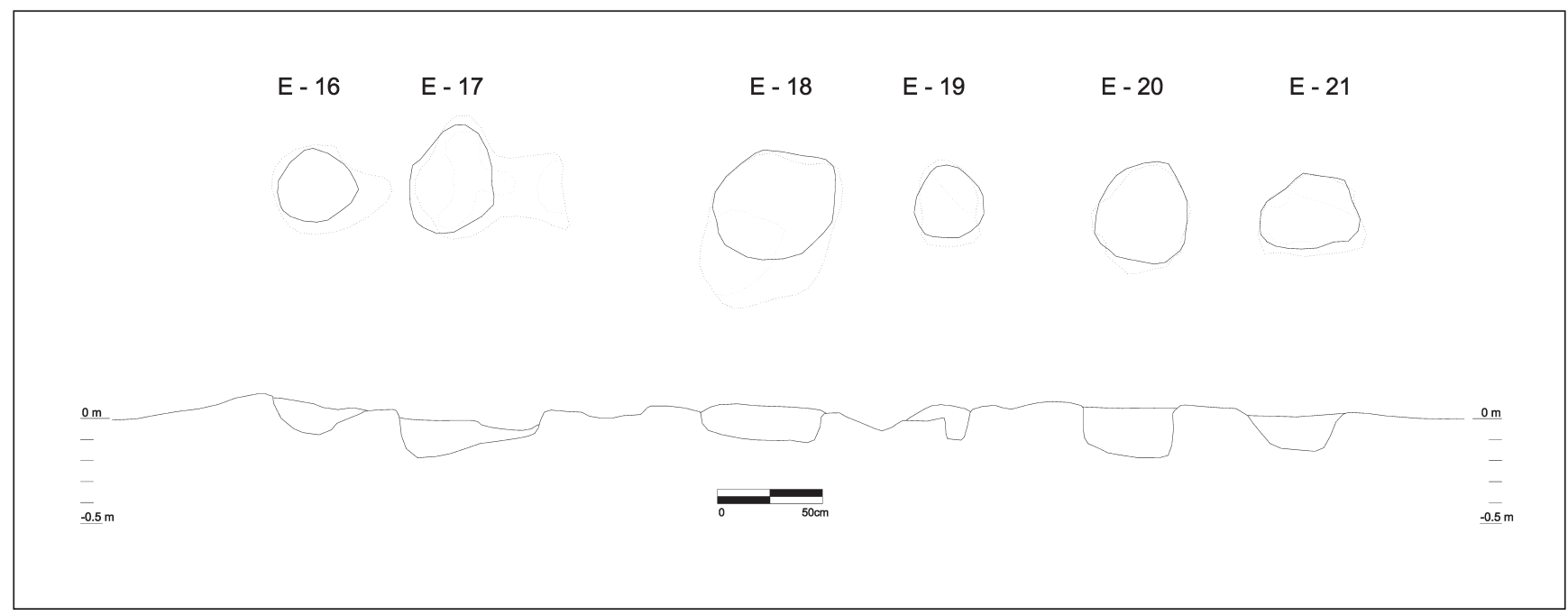

Figura 5. Seccions de forats de pal.

\section{Anàlisi de les estructures arqueològiques}

Del grup d'estructures vinculades a la pràctica d'emmagatzematge, n'hi ha 5 (E-3, E-7, E-10, E-13 i E-14) que no superen el mig metre de fondària, 5 més que van del mig metre al metre de fondària (E2, E-4, E-5, E-27 i E-28) i dues que el superen (E-9 i E-15). Algunes d'aquestes es troben situades dins l'espai delimitat pels forats de pal (E-9, E-10, E-15,
E-27 i E-28). La focalització en aquest espai permet observar que estructures molt properes, com l'E-9 i l'E-10, presenten fondàries molt desiguals, tot i disposar d'una morfologia similar, amb boques circulars, fons plans i parets còncaves de perfil troncocònic. Aquesta morfologia de fossa només es localitza en aquesta àrea específica del jaciment. Morfologia que es repeteix en l'E-15 i l'E-28, però no en l'E-27.

Per altra banda, hi ha una altra morfologia de fossa que es troba distribuïda per diferents punts del 
jaciment. Es tracta d'estructures poc profundes que disposen de boques de planta circular, fons còncaus i parets irregulars de perfil globular (E-3, E-5, E-7 i E-13).

Dues estructures més, l'E-4 i l'E-14, presenten morfologies similars amb parets rectes, base plana i perfil cilíndric, tot i que es troben força distanciades. El mateix passa amb l'E-2 i l'E-27 però, en aquest cas, disposen de boques ovalades, parets irregulars de perfil globular i fons pla.

\section{Dinàmiques d'amortització}

Tots els forats de pal del jaciment tenen un únic nivell de rebliment. Generalment, els seus rebliments acostumen a estar formats per nivells d'argila de gra fi, amb poca presència de pedres i de materials arqueològics. Tot i això, l'E-33 proporciona abundants fragments d'argila cuita, l'E-12 diversos fragments de ceràmica, indústria lítica de sílex i una pedra polida, i l'E-35 abundants restes de carbons. Amb un únic estrat de rebliment també trobem les cubetes E-29 i E-11 i tres estructures d'emmagatzematge E-7, E-10 i E-13. Per una banda, l'E-7 disposa d'un rebliment d'argila i petites pedres en el qual, a més fondària, augmenta tant el nombre com la mida de les pedres. Just al fons de la fossa, es detecta una llosa de pedra disposada de manera plana. Per l'altra banda, l'E-10 és reblerta per un únic nivell d'argila amb petites graves mentre que l'E-13 per un nivell sorrenc amb graves i blocs de pedra.

Amb dos estrats de rebliment només trobem l'E3. El nivell més superficial és format per argila amb diverses pedres, de mida mitjana $(10-20 \mathrm{~cm}$ de longitud), entre les quals trobem fragments de molins. La presència de ceràmica és escassa tot i que, en el lateral de la paret, es troba un fragment ceràmic disposat en vertical. El següent nivell, d'argila amb nombroses pedres, destaca pels abundants fragments ceràmics de mida gran. Aquests són distribuïts per tota la superfície $i$, en posició horitzontal, en vàries capes fins a assolir el fons de la fossa. El remuntatge de bona part dels fragments ceràmics permet reconstruir tot el perfil d'un gran vas ceràmic però del qual manca gairebé tota una meitat. Aquest no es troba subjectat a l'interior de l'estructura, tal com s'ha detectat en altres jaciments, com a les Escoles Nacionals (Marcet, Morral 1982) o al carrer Riereta de Barcelona (Carlús, González 2008). En aquest sentit, la presència d'un fragment de nansa i diversos fragments de paret, situats just al fons de la fossa i per sota dels fragments de la base de la ceràmica, indica clarament que el recipient no es trobava subjectat dins la fossa quan aquest es va trencar. Per altra banda, parts significatives d'aquest recipient es localitzen dins el rebliment d'una altra estructura (E-7). Aquesta circumstància vincula l'amortització de totes dues estructures que, a més a més, comparteixen uns nivells de rebliment similars, tant en composició, textura i color, com per la presència d'abundants pedres a la part més fonda. L'E-3 també proporciona diversos fragments d'ossos humans, en posició secundària. La resta òssia més gran, un fèmur, es troba en contacte amb el fons de la fos- sa, al costat de pedres i fragments ceràmics, sense indicar cap col-locació especial. Aquest presenta una perforació circular en el lateral que, a causa de la seva regularitat i textura, s'hauria fet de forma intencionada. Això implica un procés de descomposició previ, un trasllat des del lloc on el cadàver s'hauria descompost, una transformació física del fèmur i, finalment, la seva deposició final. En cap altre punt del jaciment es troben restes humanes, ni tampoc hi ha indicis de l'existència d'estructures funeràries en l'entorn immediat a l'Espina.

Altres estructures, E-4, E-9, E-14, E-27 i E-28, es troben reblertes per tres nivells. En l'E-14, el rebliment més profund és format per argila fosca, carbonets i abundants pedres. Damunt hi ha dos nivells més, formats per argiles de diferents coloracions i textures, que testimonien diferents accions $\mathrm{o}$ dinàmiques de rebliment. A l'E-28, el rebliment més profund, és format per argila vermella amb còdols, l'intermedi per argila, graves i cendres, de coloració grisenca i composició tova. La cendra no és neta, sinó que es troba barrejada amb l'argila. Finalment, el darrer és format per argila. L'E-27 proporciona tres nivells d'argila força similars però el més profund disposa d'abundants còdols. Al fons de la base de l'E-9, es troba una bossada de cendra neta amb petits carbonets $(25 \times 20 \times 10 \mathrm{~cm})$, que queda coberta per un nivell d'argila fina amb cendra dissolta, de color gris, poc compacta, i que proporciona diversos fragments d'argila cuita. Per sobre, es troba el darrer nivell, format per argila i pedres. A l'E-4, amb tres nivells de rebliment, destaca el més profund, amb presència de graves i d'una llosa de pedra, col-locada de manera plana. Per sobre es distingeixen dos nivells de rebliment més, tots tres força similars, però amb coloracions i textures diferenciades.

Amb quatre nivells de rebliment trobem l'E-2, l'E15 i l'E-5. Respecte a l'E-2, el nivell més profund, és format per argila fina, amb diverses bossades de cendra neta repartides per diferents àrees i fondàries. En una d'aquestes bossades de cendra es localitzen restes de fauna i una base de molí. Per sobre hi ha un estrat d'argila en el qual es detecta una taca d'argila amb rubefacció. El següent nivell correspon a una capa compacta de còdols i argila carbonatada, mentre que el darrer és format d'argila. Un element a destacar és la presència de 60 fragments de vores ceràmiques. L'anàlisi de les seves característiques morfològiques, tractament de les superfícies, decoracions i diàmetres, permeten identificar una quarantena de recipients ceràmics diferenciats. Només en un cas es pot reconstruir la forma del vas però la resta corresponen a petits fragments de vora. La major part de les vores corresponen a recipients de mida petita i mitjana, majoritàriament, de tendència hemisfèrica o subesfèrica. Al fons de la base de l'E-15, es troba una bossada de cendres netes $(85 \times 35 \times 10 \mathrm{~cm})$, cobertes per un nivell poc compacte de color grisenc, d'argila, graves i cendres dissoltes. Per sobre hi ha un nivell d'argila i pedres. Una d'aquestes pedres correspon a una llosa de pedra $(50 \times 25 \times 10 \mathrm{~cm})$ disposada horitzontalment. Per damunt es troba un darrer nivell d'argila fosca. La morfologia de la fossa queda afectada per un cau d'animals que forma una cavitat lateral, en 
la qual es poden observar galeries estretes, en zigzag, excavades en el natural i que enllacen amb la boca de l'estructura. Finalment, a la base de l'E-5, es troba un nivell sorrenc i petites graves, cobert per dues capes diferents d'argila les quals, a la vegada, són cobertes per un darrer nivell d'argila.

\section{Anàlisi espacial de les estructures del jaciment de l'Espina $C$}

La ubicació de les estructures dins el jaciment permet observar una distribució que no és regular ni tampoc aleatòria, sinó que presenta posicionaments dispersos i a la vegada altres de concentrats. Justament, a la zona de major concentració d'estructures, es detecten tots els forats de pal de l'assentament (25 estructures), a més de 5 sitges i una cubeta.

Els forats de pal són unes estructures que poden formar part d'una estructura de majors dimensions que es compon de tres parts: els fonaments, el nivell de circulació i una part sobreelevada. Els forats de pal formen part de la fonamentació de l'estructura sobreelevada i, precisament per això, és la part que millor es preserva. La seva distribució ens dóna informació sobre les dimensions i la morfologia d'aquesta estructura.

Els forats de pal documentats a l'Espina C són de planta circular o oval, amb diàmetres de boca entre 30 i $50 \mathrm{~cm}$ de longitud i amb fondàries entre 20 i $30 \mathrm{~cm}$. Pel que fa al perfil, n'hi ha uns de parets simètriques, rectes i verticals, i uns altres de parets sinuoses de tendència asimètrica. La base tant pot ser plana com desnivellada.

La distribució dels forats de pal en l'espai permet observar determinats alineaments que permeten suggerir un vincle comú, i que podrien formar part d'elements de fonamentació d'una estructura o construcció sobreelevada i, per tant, de funcionament simultani o sincrònic. A la vegada que també se'n detecten d'altres, de menors dimensions, que podrien formar part d'una segona construcció, molt més petita.

La primera construcció és definida per dues alineacions de forats de pal de trajectòries perpendiculars. Una, de traçat lleugerament curvilini, segueix una orientació nord-sud i està formada per 5 estructures (E-44, E-23, E-24, E-25 i E-26), mentre que l'altra, rectilínia, segueix una orientació est-oest i està formada per 6 estructures (E-16, E-17, E-18, E-19, E-20 i E-21). Ambdues alineacions defineixen el perímetre de dos dels costats d'aquesta construcció mentre que els perímetres dels altres dos costats queden més difusos.

Al sud es troba un únic forat de pal, E-36, que seria l'únic vestigi del perímetre meridional d'aquesta construcció. L'escassetat de forats de pal en aquest sector podria ser conseqüència de la superposició d'estructures, corresponents a l'època moderna i contemporània, les quals haurien pogut fer desaparèixer les estructures prehistòriques menys profundes. En aquest sentit, entre el forat de pal E-36 i el més meridional de l'alineació oriental E-44, transcorre una rasa de vinya de trajectòria est-oest i una fossa rectangular vinculada a la plantació d'arbres. D'altra banda, entre l'E-36 i l'E-45 —el forat de pal més meridional de l'alineació occidental— també hi ha una

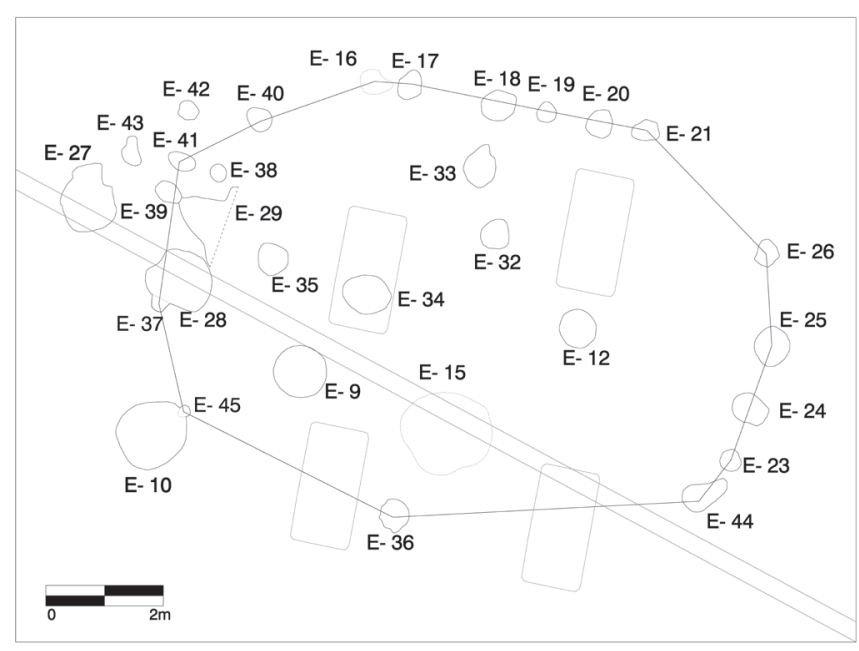

Figura 6. Planta de l'estructura formada per forats de pal.

fossa rectangular vinculada a la plantació d'arbres. Aquestes circumstàncies podrien justificar l'absència de forats de pal en el perímetre meridional.

A la zona de ponent trobem 8 forats de pal però no tots es troben en posició lineal. N'hi ha quatre de dimensions similars a la resta de forats de pal (E-37, E-40, E-41 i E-45) i quatre més (E-38, E-39, E-42 i E-43) amb volums clarament inferiors. Precisament, la posició d'aquests més petits no coincideix amb l'alineament de la resta de forats de pal, a excepció de l'E-39. En aquest sentit, l'E-38 es troba desplaçat cap a l'interior del perímetre de la construcció mentre que, l'E-42 i l'E-43, cap a l'exterior. Tanmateix, tots quatre mantenen un posicionament regular, respectant la mateixa distància entre cadascun d'ells, d'entorn $1 \mathrm{~m}$ de distància. És per això que podrien pertànyer a una altra construcció, de menors dimensions, potser de planta quadrangular. La resta de forats de pal d'aquest sector es vincularien amb la primera construcció i formarien part del perímetre ponentí.

A l'interior de la construcció més gran trobem 5 forats de pal més. Dos d'aquests, E-12 i E-34, es troben situats en una posició cèntrica i equidistant, tant entre ells, com vers els forats de pal perimetrals. Ambdós forats de pal mantenen una distància de separació de 3,44 metres. L'E-12 manté una distància de 3,3 metres respecte l'E-25 i 3,5 metres vers l'E-20. L'E-34 dista 3,7 metres tant de l'E-37 com de l'E-36 i 3,6 metres de l'E-17. L'equidistància observada entre aquests i vers els perimetrals, permet interpretar-los com els encarregats d'encabir els pilars que sostindrien la coberta de la construcció; punt on recolzarien els travessers els quals, per l'altre extrem, es recolzarien damunt dels pilars perimetrals. Els altres forats de pal interns (E-32, E33 i E-35) no es troben en una posició equidistant respecte els forats de pal del perímetre, i podrien correspondre a elements de reforç per al sosteniment de la coberta, de suport d'estructures menors, o bé també podrien suggerir l'existència d'àrees diferenciades.

4. Distàncies calculades a partir del punt central de cada estructura. 
Així, la distribució alineada de determinats forats de pal, conjuntament amb l'associació espacial d'altres, ha permès de vincular-los com a parts integrants de la fonamentació d'una construcció àrea feta de material periple. Es tracta dels forats perimetrals E-16, E-17, E-18, E-19, E-20, E-21, E-23, E-24, E-25, E-26, E-36, E-37, E-40, E-41, E-44 i E-45 i dels forats interns E-12, E-32, E-33, E-34 i E-35. Tots aquests forats de pal funcionarien de manera sincrònica, com a parts constituents d'una mateixa estructura. D'aquesta manera, s'interpreta que, entre pilar i pilar, hi hauria un entramat que tancaria el perímetre i una coberta al damunt que seria sostinguda pels forats de pal interns. L'accés, però, no queda definit. Aquesta construcció mesura 7,3 m d'amplada, 10,4 $\mathrm{m}$ de llargada i disposa d'un espai intern d'uns $70 \mathrm{~m}^{2}$ aproximadament. Tanmateix, la definició geomètrica de la planta de l'edificació no és del tot exacta, ja que si la unió entre els forats de pal es fa a partir de traços corbs, adopta una planta oval i més trapezoïdal quan aquests són rectes. La seva funcionalitat, però, és incerta, pel fet que no s'ha conservat el nivell d'ús original, ni tampoc indicis d'altres estructures associades, com podrien ser llars, banquetes, àrees de treball, etc.

Aquest tipus de construcció, feta de material perible i sostinguda per una sèrie de troncs clavats al subsòl, deixa en el registre arqueològic una sèrie de forats de pal distribuïts de tal manera que, a vegades, és possible reconstruir-ne el perímetre. Aquestes construccions es documenten ja en el Neolític, en jaciments com Mas d'Is (Penàguila) (Bernabéu et al 2003), la Velilla (Palència) (Delibes, Zapatero 1996), La Deseada (Rivas-Vaciamadrid) (Díaz-del-Río, Consuegra 1999), La Draga (Banyoles) (Bosch et al. 2000) o La Serreta (Vilafranca del Penedès) (Esteve et al. 2012). En el Neolític Final-Calcolític es documenten forats de pal en diversos jaciments, encara que no sempre és possible vincular-los amb una cabana, podria ser el cas de Riera de Masarac (Tarrús, Chinchilla 1985), de la Prunera (Alcalde et al. 2005) o Camp del Rector (Font 2005). Del període Calcolític-bronze han estat adscrits 34 dels 184 forats de pal localitzats al Bosc del Quer (Carlús, De Castro 2014). A la península Ibèrica trobem els exemplars de Camino de las Yeseras (Madrid) (Liesau et al. 2008), Fuente Celada (Burgos) (Alameda et al. 2011) o El Hornazo (Burgos) (Carmona 2012).

En el període del bronze en trobem una a Minferri (Juneda) (López 2001), almenys dues de rectangulars a Mas Bonet (Vilafant) (Rosillo et al. 2012), diversos forats de pal a l'Institut de Manlleu (Boquer et al. 1995), una cabana a Teso del Cuerno (Salamanca) (Martín, Jiménez 1988-1989) i possiblement una altra a Celada del Camino (Burgos), tot i que la seva cronologia no ha estat confirmada (Villanueva et al. 2012). També es documenten estructures excavades al subsòl amb forats de pal interns a Can Roqueta II (Palomo et al. 2002) i Minferri (Equip Minferri 1997). Per altra banda, a Mas d'en Boixos, es localitzen 38 forats de pal els quals són de difícil adscripció cronològica (Bouso et al. 2004).

A la Meseta Central, durant la transició del bronze final a la primera edat del ferro, trobem nombroses cabanes fetes amb forats de pal que presenten unes característiques força similars a la cabana de l’Espina C. Algunes són més allargades i reben el nom de longhouse però d'altres presenten unes dimensions similars. En trobem als jaciments de Las Camas (Urbina et al. 2007), Cerro de San Antonio, Sector III de Getafe, Los Pinos (Muñoz, Ortega 1997), Pico Buitre (Valiente, Malla 1984), La Cuesta (Flores, Sanabria 2012), Las Lunas (Urbina, Urquijo 2012), La Guaya (Misiego et al. 2005) o Albareja (Consuegra, Díazdel-Río 2007) les quals són datades entorn de final del segon mil.lenni i principi del primer. També al camí dels Banys de la Mercè (Rosillo et al. 2012) es documenten 67 forats de pal que podrien configurar cabanes rectangulars. La datació d'un d'aquests forats de pal situa la construcció entre el 650-770 cal aC.

Els altres forats de pal no alineats, E-38, E-39, E-42 i E-43, podrien formar part d'una segona construcció de dimensions molt menors respecte de la primera. La projecció dels perímetres de les dues construccions se sobreposen, de tal manera que podrien haver estat bastides en diferents moments, però sense poder determinar quina és anterior o posterior a l'altra. Es desconeix la funcionalitat d'aquesta construcció, tot i que construccions similars s'han vinculat a graners elevats (Flores, Sanabria 2012), on s'emmagatzemen vegetals en una atmosfera renovada (Alonso 1999: 201), a espais per col-locar recipients ceràmics, assecar el gra al sol o posar el pinso dels animals (Bellido 1996: 28).

\section{Les superposicions d'estructures}

En l'entorn immediat de la construcció aèria trobem 5 sitges (E-9, E-10, E-15, E-27 i E-28) i una cubeta (E-29). La resta d'estructures del jaciment queden molt distanciades, només una queda a una posició intermèdia (E-14), a $7 \mathrm{~m}$ de distància del perímetre ponentí de la construcció.

Les relacions estratigràfiques observades en el registre de camp han permès identificar superposicions d'estructures. Concretament, els forats de pal E-45 i E-37, els quals formen part del perímetre ponentí de la construcció aèria, tallen les sitges E-10 i E-28, respectivament. Un, forat de pal E-37, talla la paret meridional de la sitja E-28 i l'altre, forat de pal E-45, talla la paret septentrional de la sitja E-10. Aquestes superposicions han estat registrades, ja que les fosses dels forats de pal han quedat fossilitzades, com empremtes en negatiu, en la part superior de les parets laterals de les sitges. Aquestes relacions físiques indiquen que els forats de pal van ser realitzats una vegada les sitges havien estat completament amortitzades. Per tant, el funcionament dels forats de pal, és a dir, de la construcció aèria, és posterior al de les dues sitges i constata una relació diacrònica entre aquestes estructures arqueològiques.

\section{Anàlisi del material arqueològic}

\section{Els remuntatges}

Es portà a terme una recerca de possibles remuntatges entre els materials arqueològics recuperats en els rebliments de les diferents estructures, a fi de poder vincular el funcionament de diverses estructures 
inconnexes físicament entre elles. Aquesta recerca se centrà en tots els materials arqueològics, però només la ceràmica ha permès de detectar remuntatges.

El remuntatge de fragments ceràmics provinents de diferents estructures arqueològiques ha estat possible gràcies a l'observació de les característiques de les pastes, dels desgreixants, del color, dels acabats de les superfícies i de les decoracions, que a nivell ocular han permès veure similituds entre diversos fragments. Després es comprovà la seva vinculació a través de la unió física. Per una banda, es detecta remuntatges de fragments ceràmics provinents dels rebliments de l'E-3 i l'E7 i, per l'altra banda, també entre els fragments de les estructures E-10 i E-15.

Aquests remuntatges permeten relacionar les dinàmiques de rebliment de dues estructures diferenciades $\mathrm{i}$, per tant, evidencien unes relacions de sincronia en el seu moment de clausura. Pel fet que les sitges no es poden deixar gaire temps en desús, ja que els agents atmosfèrics les malmetrien i les reblirien, el remuntatge permet interpretar que cada parella d'estructures funcionarien de manera sincrònica.

\section{Els materials arqueològics}

\section{La ceràmica}

El jaciment de l'Espina C ha proporcionat 904 fragments ceràmics fets a mà corresponents al període de la prehistòria recent.

\section{Estructura 2}

Proporciona 276 fragments ceràmics que representen el $38 \%$ del total del registre ceràmic, amb un gruix mitjà de $8,12 \mathrm{~mm}$ de paret. Per la superfície externa predomina l'acabat polit mentre que per la interna l'allisat. Hi ha 45 vores, amb un diàmetre mitjà de boca de $17,5 \mathrm{~cm}$, de les quals el $16 \%$ són obertes, el $33 \%$ rectes i el $51 \%$ tancades (figura 8 ).

El $15 \%$ de les vores es troben associades a llengüetes (figura 8, 1, 12, 14 i 16) i en un cas a un mugró (figura 8, 9). En cinc casos aquestes aplicacions es troben a menys d'un centímetre del llavi $i$ en dos casos, a més de $2 \mathrm{~cm}$ del llavi. Els motius decoratius són molt escassos i són formats, exclusivament, per un o varis cordons llisos de trajectòria paral-lela (figura 8, 11). Només s'identifiquen 15 fragments de base, la major part còncaus però també tres de plans.

\section{Estructures 3 i 7}

Els materials ceràmics recuperats en els rebliments de les dues estructures han permès reconstituir un vas ceràmic (figura 7,5 ), fet que indica que totes dues estructures van tenir un ús secundari sincrònic. L'E-3 només proporciona materials ceràmics corresponents a aquest vas ceràmic, mentre que l'E-7, a més d'una desena de fragments d'aquest, també aporta 25 fragments de ceràmica. Ambdues estructures aporten el 3,4 \% de la ceràmica del jaciment. El gruix mitjà de tots els fragments ceràmics és de $8 \mathrm{~mm}$, amb un predomini de l'acabat allisat tant en la superfície interior com exterior. Hi ha 7 vores orientades cap a l'interior amb llavis arrodonits amb un diàmetre mitjà de boca de $17 \mathrm{~cm}$ i de les quals 5 són de perfil exterior rectilini. Les vores no es troben decorades ni tampoc associades a cap tipus d'aplicació plàstica (figura 7, 1-3). Tanmateix, a la panxa dels recipients es detecten dos fragments amb cordó llis de relleu suau i un fragment amb 2 cordons força amples de traçat paral.lel. També hi ha dues nanses, una de vertical i una altra en forma de llengüeta amb dues perforacions verticals (figura 7,4 ).

\section{Estructura 4}

Només proporciona 18 fragments ceràmics que representen el 2,4\% del total del conjunt, amb un gruix mitjà de paret de $8,6 \mathrm{~mm}$. En la superfície externa predomina l'acabat polit mentre que en la interna l'allisat. Hi ha tres vores orientades cap a l'interior i dues de rectes. Només un fragment informe es troba decorat per una línia curvilínia esgrafiada, efectuada després de la cocció. Hi ha un únic fons de perfil còncau.

\section{Estructura 5}

Només trobem 6 fragments informes de ceràmica que representen el $0,9 \%$ del total, amb un gruix mitjà de paret de 7,6 mm. Hi ha un predomini de l'acabat allisat respecte del polit, sobretot en la cara interna. No hi ha cap decoració ni elements de prensió.

\section{Estructura 9}

Es troben 103 fragments de ceràmica que representen el $14 \%$ del total, amb un gruix mitjà de paret de $8,6 \mathrm{~mm}$. Tant a la cara externa com interna de les ceràmiques predomina el polit respecte l'allisat. Hi ha 5 vores orientades a l'interior i una altra de recta (figura 7, 6). Lúnica vora decorada presenta dos motius decoratius, impressions ovals damunt el llavi i línies incises a la paret exterior. Es troben 8 fons de ceràmica plans i un de còncau.

\section{Estructura 10}

Els 48 fragments ceràmics recuperats representen el $6,5 \%$ del total, amb un gruix mitjà de paret de $8,8 \mathrm{~mm}$. L'acabat allisat és el predominant tant en la cara externa com en la interna. Hi ha 1 vora orientada cap a l'exterior i 5 de rectes, una de les quals amb un mugró cònic. També 3 fragments de fons dels quals 2 són de perfil còncau i 1 és pla.

\section{Estructura 11}

Els 9 fragments ceràmics recuperats representen l'1,2\% del total, amb un gruix mitjà de $7,4 \mathrm{~mm}$. L'acabat polit predomina en la cara externa però en la interna predomina l'allisat sobre el polit. Hi ha dues vores orientades cap a l'exterior i una base plana (figura 7, 9-10).

\section{Estructura 13}

Proporciona 8 fragments de ceràmica que representen l'1,09\% del total, amb un gruix mitjà de paret 


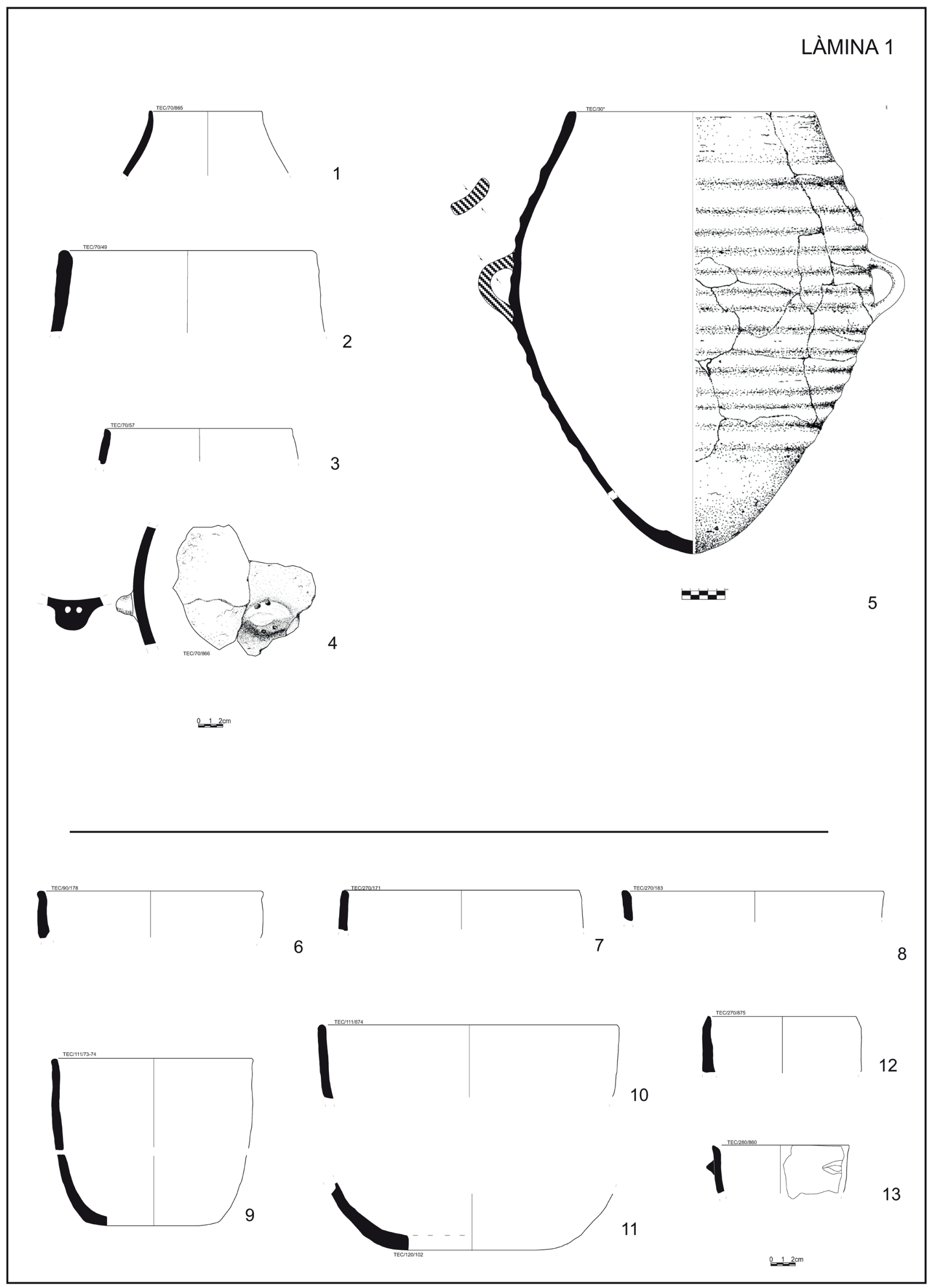

Figura 7. Làmina 1 de dibuix dels materials ceràmics. 
de 7,5 mm. Lacabat de les superfícies ceràmiques és allisat però hi ha un exemplar amb raspallat intern. No es troba cap element de decoració ni tampoc cap element de prensió.

\section{Estructura 14}

S'han comptabilitzat 46 fragments ceràmics que representen el 6,3\% del total de la ceràmica, el gruix mitjà és de $8,9 \mathrm{~mm}$. Lacabat allisat predomina tant en la superfície externa com interna. Entre aquests fragments hi ha 6 vores orientades cap a l'interior i 6 de rectes. Quatre de les vores es troben decorades per un petit cordó llis de secció arrodonida, situat entre 1 i $2 \mathrm{~cm}$ sota del llavi. Dues vores més disposen de dos arrencaments de mugró situats a $1 \mathrm{~cm}$ sota el llavi. Hi ha una nansa orientada en sentit vertical i una base plana.

\section{Estructura 15}

Hi ha un total de 72 fragments ceràmics que representen el 9,8\% del total de la ceràmica de l'Espina C. Trobem 7 vores amb un diàmetre mitjà de boca de $18,1 \mathrm{~cm}, 3$ bases planes i 2 de còncaves. No es documenta cap nansa ni tampoc cap element plàstic per a la subjecció del recipient. Els motius decoratius en la ceràmica són absents. El gruix mitjà dels fragments ceràmics és de $8,4 \mathrm{~mm}$. En l'acabat de les superfícies ceràmiques predomina el polit.

\section{Estructura 27}

S'han comptabilitzat 64 fragments de ceràmica que representen el $8,7 \%$ del total del registre ceràmic, amb un gruix mitjà de $8,4 \mathrm{~mm}$ de paret. Lacabat allisat és majoritari respecte del polit. De les 9 vores recuperades, 4 són rectes, 3 tancades i 2 obertes (figura $7,7,8,12$ ). El diàmetre mitjà de les boques dels recipients és de 15,7 cm. Només una vora es troba decorada per dues línies incises paral-leles de traç molt suau. Es detecten 3 bases planes i 3 més de còncaves.

\section{Estructura 28}

Es recuperaren 29 fragments ceràmics que representen el 3,9\% del total de l'Espina C. Entre aquests es troben 7 vores amb un diàmetre mitjà de boca de $12,8 \mathrm{~cm}$, una base plana i una altra de còncava. Com a element decoratiu es detecta un únic mugró pessigat, situat a menys d'1 $\mathrm{cm}$ del llavi d'una vora (figura 7,13 ). El gruix mitjà és de $7,5 \mathrm{~mm}$. En la superfície exterior predomina l'acabat polit i en la interior l'allisat.

\section{Els forats de pal}

Els forats de pal amb materials ceràmics són els següents: E-12, E-17, E-21, E-24, E-25, E-33, E-35 i E-41. Proporcionen 17 fragments de ceràmica que representen el 2,3\% del total, amb un gruix mitjà de $8,7 \mathrm{~mm}$. Hi ha un predomini de l'acabat allisat en la superfície interna i externa de les ceràmiques. Es troba una base plana (figura 7,11 ), un fragment informe amb tres petits traços incisos i un fragment de petit cordó llis amb superfícies raspallades.

\section{La cronologia relativa dels materials arqueològics}

Les característiques morfològiques i decoratives de les ceràmiques prehistòriques han permès de caracteritzar tres conjunts o produccions ceràmiques diferenciades. Tot i així, algunes de les estructures no han pogut ser ubicades a cap d'aquests conjunts per manca d'elements cronoculturals significatius, és el cas de les estructures E-4, E-5, E-6, E-9, E-10, E-14, E-15, E-28 i tots els forats de pal.

\section{El primer conjunt de ceràmiques}

Aquest primer conjunt es detecta en tres estructures (E-3, E-7 i E-13). D'aquest primer conjunt es disposa d'una única forma sencera (figura 7,5 ) que fa $51 \mathrm{~cm}$ d'alçada, $28 \mathrm{~cm}$ de diàmetre de boca i 42 $\mathrm{cm}$ de diàmetre màxim a mitja altura de la peça. Es tracta d'una forma ovoide de vora reentrant, base convexa i amb nanses de cinta situades a la part mitjana del cos. És decorat per múltiples cordons llisos horitzontals que pràcticament cobreixen tota la superfície exterior. En contexts ceràmics epicardials i postcardials trobem grans recipients ceràmics, de característiques formals similars, però amb elements morfològics diferents com a la Cova 120 (Agustí et al. 1987), Cova de l'Or (Granados 1981: figura 2.6), Forat de Conqueta (González 2010: figura 7), Coll de Porta (Alòs 1990) i a les capes 10 i 11 de la Cova de Can Sadurní (Edo et al. 2011: figura 10). També en trobem un de similar a la Feixa del Moro (Juberri) (Llovera, Colomer 1989: 38) del Neolític mitjà.

Els vasos decorats amb cordons llisos es troben al llarg de tot el període neolític. Tanmateix, en contexts epicardial i postcardial, trobem ceràmiques en què els cordons llisos, en horitzontal, es distribueixen de manera successiva per bona part de la superfície del vas com al Pla del Gardelo (Piera 2010: làm. 2, 1-2), Cova del Parco (Petit 1996: figura 15, 7), Cova de la Font del Molinot (Baldellou, Mestres 1977: làm. I), la Timba del Bareny (Romero, Miró 1993: làm. 1), el Barranc de Fabra (Bosch et al. 1996: 393), Mines de Can Tintorer (Villalba et al. 1986: figura 53, 3) o Cova de l'Avellaner (Bosch, Tarrús 1990: figura 56, 18 , figura 65,29 ).

També trobem altres elements ceràmics significatius, com és una llengüeta amb doble perforació (figura 7, 4), fragments decorats amb cordons llisos i les superfícies de les parets raspallades.

De la llengüeta amb doble perforació en vertical, en trobem exemplars a la Cova de les Encantades de Martís (Tarrús 1982: figura 10, 73), a la Cova de les Grioteres (Castany 1995: figura 12), Cova de l'Or (Granados 1981: figura 4, 2), Ca n'Isach (Tarrús et al. 1996: figura 5) i Mina 7 de Can Tintorer (Villalba et al. 1986: figura 27).

Les superfícies raspallades es comencen a trobar en contexts ceràmics epicardials, però és en els postcardials quan assoleixen una màxima representació, sobretot dins l'estil Molinot. A Catalunya apareixen 
en nombrosos jaciments de la costa central, entre el Llobregat i el Gaià (Mestres 1988-1989: 125) com és el cas de Cova Font del Molinot, la Cova Can Sadurní o Hort d'en Grimau. Tanmateix, aquesta ceràmica de superfícies raspallades apareix en altres àrees de Catalunya, a la comarca de l'Anoia la trobem als Vilars de Tous (Clop et al. 2005: 554), a la Conca de Barberà a Molins de la Vila (Adserias et al. 2003: 185), a les Garrigues al Collet de Puiggròs (Piera 2008: 35).

Per tant, la cronologia relativa d'aquest conjunt de materials encaixa amb les ceràmiques que apareixen en contexts postcardials, justament, en aquest moment de transició entre el Neolític antic i el mitjà. Les formes d'aquests vasos de l'Espina $C$ són pròpies d'aquest moment postcardial, les superfícies raspallades d'algunes ceràmiques podrien vincular-se a l'estil Molinot, mentre que l'orella amb doble perforació podria ser una influència de tradició Montboló. També és destacable la decoració de cordons llisos horitzontals, disposats per gairebé tot el cos del recipient i que es documenta en altres jaciments d'aquest moment.

\section{El segon conjunt de ceràmiques}

És format per un conjunt força fragmentat de ceràmiques que no proporciona cap forma sencera, tot $\mathrm{i}$ que trobem diverses vores que conserven bona part del perfil de la peça. Aquest segon conjunt de ceràmiques només s'identifica a l'E-2.

Una d'aquestes vores (figura 8, 1), de $15 \mathrm{~cm}$ de diàmetre de boca, presenta una forma de tendència esfèrica, amb una llengüeta que se situa en el coll, lleugerament diferenciat. Les superfícies són allisades. N'hi ha de similars a la Cantorella (Escala et al. 2014) i Can Vinyalets (Font 2006: figura 12).

5 vores més presenten uns perfils que permeten intuir una forma de tendència esfèrica, parets curvilínies, amb diàmetres de boca que van dels 21 als $30 \mathrm{~cm}$ i diàmetre màxim a mitja altura del vas (figura $8,4,10,13,15$ i 17). No hi ha cap element de prensió ni decoració. A la plana occidental catalana trobem diversos exemplars similars a la Cantorella, a la Balma del Clotar (Gallart, Ribes 2001: figura 6) i Balma d'Ollers (González 2010).

Un altre grup de vores, format per 4 exemplars (figura 8, 2, 3, 9 i 12), que corresponen a recipients de forma més o menys cilíndrica, amb vores rectes o lleugerament obertes i amb diàmetres de vora entorn els 13 i $15 \mathrm{~cm}$. Alguns d'ells es troben decorats amb llengüetes allargades o bé amb mugrons circulars sota la vora. A la plana occidental catalana en trobem a la Cantorella (Escala et al. 2014) i a la Balma de Solans de Recots, però també apareixen en altres punts de Catalunya com a Can Vinyalets (Font 2006: figura 12), Cova Can Sadurní (Edo et al. 2011, figura 13), Mas Bonet (Rosillo et al. 2010: figura 4) i Reina Amàlia 16 (Bordas, Salazar 2006: Imatge 4).

Altres elements a destacar d'aquest grup de ceràmiques són els fragments informes decorats amb múltiples cordons llisos, en el cas de l'Espina C, aquests són més marcats, és a dir, de menor amplitud i de major relleu respecte dels exemplars postcardials. A la plana occidental catalana en trobem a la Torre
Garrell (Clop et al. 2006a: 89) al Morro de Vilanova (Torres de Segre, Segrià) (Clop et al. 2006b) i a les Roquetes (Gallart, Ribes 1988: làm. I, 19). També n'hi ha al Collet de Brics d'Ardèvol (Castany et al. 1992: 24, 4), Riera de Masarac (Tarrús, Chinchilla 1985: figures 6 i 7), Cova Joan d'Os de Tartareu (Martin 1977: figura 3, 7), Mas Bonet (Rosillo et al. 2010: fig. 4) i Can Llobateres (Martin 1977: figura 4, 5).

Totes aquestes formes, elements morfològics i decoració són propis del període del Neolític final-Calcolític de la plana occidental catalana i també de Catalunya. Algunes de les formes ceràmiques i determinats elements funcionals i/o decoratius, com ara les llengüetes sota el llavi o els cordons llisos, es troben presents en conjunts verazians. Tanmateix, no es detecta un dels elements més definitoris d'aquest estil, com és la presència de dues llengüetes o orelles superposades $i$ distribuïdes diametralment pel cos del vas.

\section{El tercer grup de ceràmiques}

Es troben en els rebliments de les estructures E-27 i E-11. Les formes d'aquest grup també són escasses a causa de l'alta fragmentació de la ceràmica. Tot i això, es detecta una forma amb gairebé tot el perfil sencer. Es tracta d'un recipient de forma lleugerament troncocònica (figura 7, 9), de $16 \mathrm{~cm}$ de diàmetre de boca i amb base plana d'11 cm de diàmetre, el qual es troba sense decoració. Un altre fragment de vora (figura 7,10 ) podria pertànyer a un vas de la mateixa forma que l'anterior, però amb unes dimensions més grans. És una forma molt freqüent a l'època del bronze i en trobem en nombrosos jaciments tant a la plana occidental catalana com a tot Catalunya. Així, en trobem de similars als jaciments de la Cantorella (Escala et al. 2014: figura 14, 5), a Vincamet (Moya et al. 2005: figura 26), Genó (Maya et al. 1998: figura 74, forma 4), els Llirians del Mas (Piera et al. 2013: figura 17, 5), el Poliesportiu UAB (Francès 1995: figura 10, 6 i 10) i Can Roqueta II (Carlús et al. 2008: figura 10).

Altres elements significatius d'aquest conjunt són les bases planes i, de manera testimonial, l'acabat fet amb grumolls d'argila cuita a l'E-11.

La major part de fragments de vores, bases i decoracions es troben molt fragmentats i tots els elements analitzats presenten unes característiques poc definidores per a la seva adscripció cronocultural. Tot i això, presenten unes característiques formals i decoratives pròpies de la ceràmica genèrica del bronze inicial a Catalunya. Tanmateix, l'escassetat de decoracions i dels acabats rugosos d'argila cuita en les superfícies de les ceràmiques, podrien indicar un moment de transició cap al bronze final, però sense trobar cap element morfològic i decoratiu exclusiu de les ceràmiques d'aquest període.

\section{Les ceràmiques dels forats de pal}

Els forats de pal han aportat un reduït nombre de fragments ceràmics, amb escasses formes i motius decoratius. Un fragment informe decorat amb cresta i raspatllats, recuperat dins l'E-33, és un motiu decoratiu afí al neolític postcardial mentre que una base plana recuperada dins l'E-12 es vincularia més 


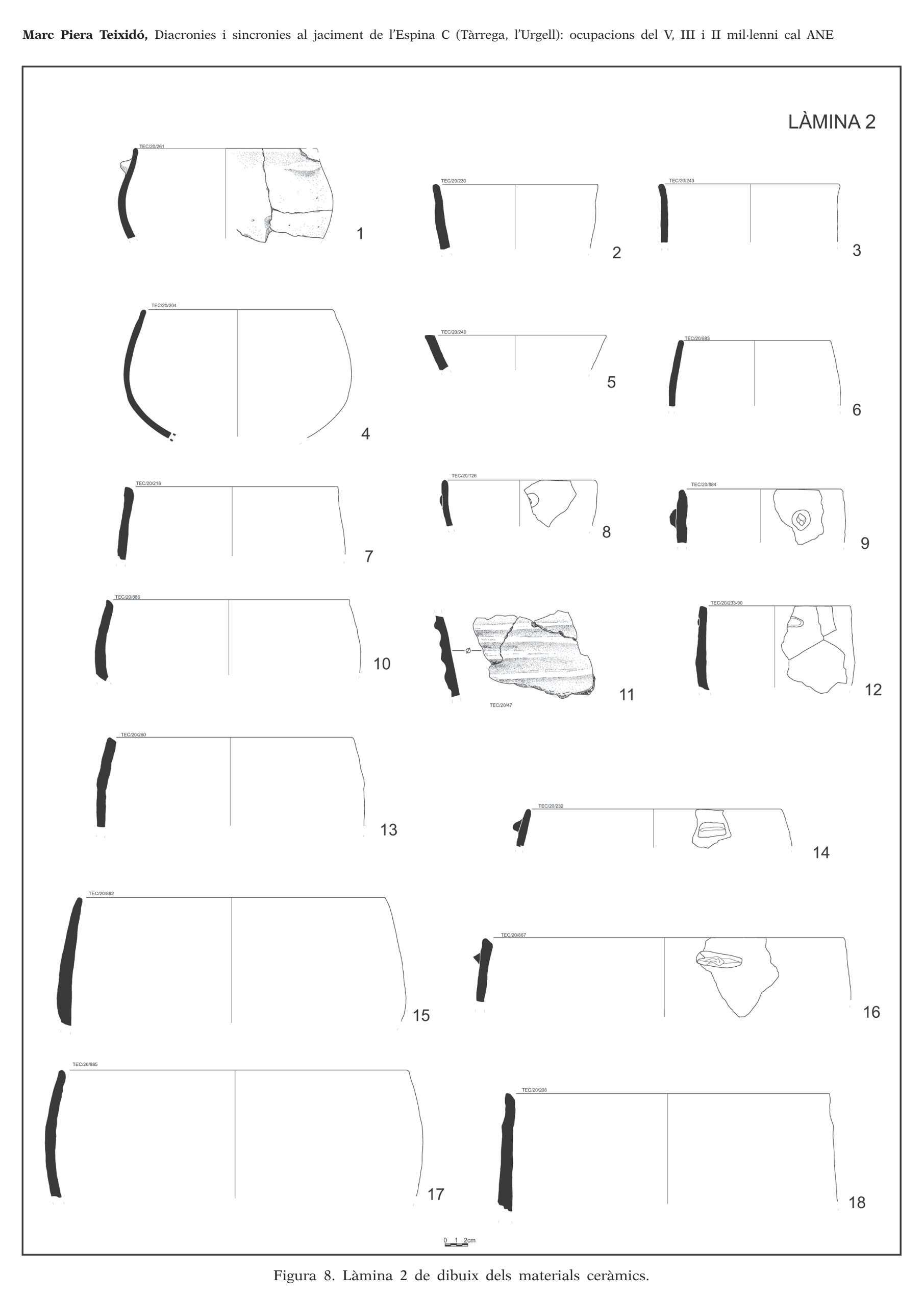


al període del bronze. També es recuperà un petit fragment amb petits traços incisos a l'E-25, però de difícil valoració al respecte. Per altra banda, observem que determinats forats de pal tallen les sitges 10 i 15, motiu pel qual aquests han de ser posteriors. Tanmateix, els materials ceràmics vinculats a aquestes sitges no permeten determinar-ne l'atribució cronocultural.

Tot i la troballa d'un fragment ceràmic del període postcardial dins d'un forat de pal, no es pot assegurar que aquestes construccions siguin d'aquest període, ja que hi ha la possibilitat de filtració, en tractar-se d'un espai on prèviament hi havia hagut una ocupació postcardial. Tampoc no s'ha datat cap dels forats de pal ni cap de les dues sitges tallades per aquests, fet que, de moment, no podem determinar la cronologia d'aquestes construccions.

\section{La indústria lítica}

L'instrumental lític de l'Espina C és compost per un nucli, 35 esclats, 19 làmines i 15 fragments informes. El $79 \%$ d'aquestes peces estan fracturades i confeccionades a partir de diferents varietats de sílex. La majoria són realitzades amb sílex blanquinós o grisenc de gra gruixut, però també es detecta la presència minoritària d'un sílex de gra fi, de coloracions marrons. Hi ha 11 instruments retocats dels quals 5 són esclats, 5 làmines i un fragment informe amb un tall retocat. Tipològicament trobem làmines amb retocs laterals, i entre els esclats, un denticulat i un escatat. Un cas especial el constitueix una peça que presenta fractura distal i un tall dret retocat bifacialment que podria correspondre a una falç en procés d'elaboració. Aquesta indústria lítica és perfectament atribuïble als períodes del Neolític i bronze. En aquest sentit no es documenten peces singulars com podrien ser, per exemple, els elements de projectil de retoc pla que podrien indicar un horitzó del Neolític final-Calcolític.

Les peces macrolítiques són escasses i la major part de les peces són fragments que representen menys de la quarta part de la superfície total de la mola. La morfologia d'aquests fragments de peces es troben tant en contexts neolítics com del bronze. Aquestes peces apareixen en les estructures E-2, E-3, E-7, E-9 i E-14. Altres pedres recuperades corresponen a útils que presenten superfícies repicades o polides i que es vinculen a destrals de pedra polida. Es recuperaren en les estructures E-2, E-7, E-12 i E-28.

\section{L'argila cuita}

Hi ha fragments d'argila cuita en els rebliments de les estructures E-2, E-9, E-15, E-28, E-29, E-33 i E-35. Dos d'aquestes estructures formarien part de la mateixa cabana per correspondre a forats de pal interns (E-33 i E-35), les altres es distribueixen en l'entorn d'aquesta construcció, a excepció de l'E-2, que es troba força distanciada. Tot i això, l'E-15 i l'E-28 són anteriors a la cabana. Per aquest motiu, no hi ha una clara associació entre aquests fragments d'argila cuita amb la cabana, sinó que la seva presència acostuma a anar associada a nivells d'argila amb cendres. Aquesta associació podria indicar una procedència relacionada amb la neteja de les àrees de combustió més que a elements constructius de la cabana.

\section{La cronologia absoluta}

Hi ha tres datacions radiocarbòniques corresponents al jaciment de l'Espina C. Una vinculada a l'E-2 (Piera et al. 2009). Posteriorment, en el marc del Treball de Fi de Màster, sobre la ceràmica del jaciment de l'Espina C, es realitzaren dues noves datacions absolutes gràcies al finançament proporcionat pel Grup Recerca Arqueològica del Mediterrani i del Pròxim Orient (2014 SGR 1248) de la Universitat Autònoma de Barcelona. Una vinculada a l'E-3 i l'altra a l'E-27. Les datacions radiocarbòniques certifiquen almenys l'existència de tres ocupacions humanes diferenciades i dilatades en el temps dins un mateix espai físic:

\section{Primera ocupació de l'assentament}

- L'E-3 és datada a partir de diversos petits fragments de fauna corresponents a mamífers de talla gran no identificats, recuperats a l'interior de l'estrat de rebliment més profund de l'estructura (UE 31). El resultat és el següent: Beta $385146=\mathbf{5 . 2 7 0 + - 3 0}$ BP (4325-4285 cal BC). En aquest mateix estrat es recuperà un recipient ceràmic (figura 7,5 ), amb forma, acabats i decoració que encaixa bé amb la ceràmica del període postcardial, en transició entre el període del Neolític antic i mitjà.

\section{Segona ocupació de l'assentament}

- L'E-2 és datada a partir d'una falange de Bos taurus extreta dins l'estrat de rebliment (UE 24) que és el més profund de l'estructura 2. El resultat és el següent: Beta-247384= 4.120+-40 BP (2 sigma 2870-2570 cal BC). El material ceràmic associat (figura 8) presenta unes formes, decoracions i acabats que es poden ubicar dins els estils ceràmics del Neolític final-Calcolític.

\section{Tercera ocupació de l'assentament}

- L'E-27 és datada a partir d'un fragment de diàfisi d'húmer de Bos taurus extreta del darrer nivell de rebliment de l'estructura (UE 270). El resultat és el següent: Beta-385145= 3.130+-30 BP (1530-1425 cal BC). El material ceràmic associat és escàs i la major part correspon a fragments informes poc significatius (figura 7, 7, 8, 12). Els elements formals, les decoracions i els acabats són similars als materials genèrics del bronze inicial en transició al bronze final. Dins el context de la plana occidental catalana, aquests materials encaixen bé amb els contexts ceràmics del Grup Segre Cinca-I. El resultat de la datació radiocarbònica i el material recuperat és coherent.

\section{Discussió}

La distribució de les sitges mostra que les de perfil troncocònic i, generalment, de més fondària es troben agrupades en una zona específica. Aquest fet podria ser un indici de l'existència d'un vincle cronològic entre aquestes estructures, tot i que no ha pogut ser contrastat.

Lanàlisi de les dinàmiques de rebliment mostra que els forats de pal es troben reblerts per un únic 


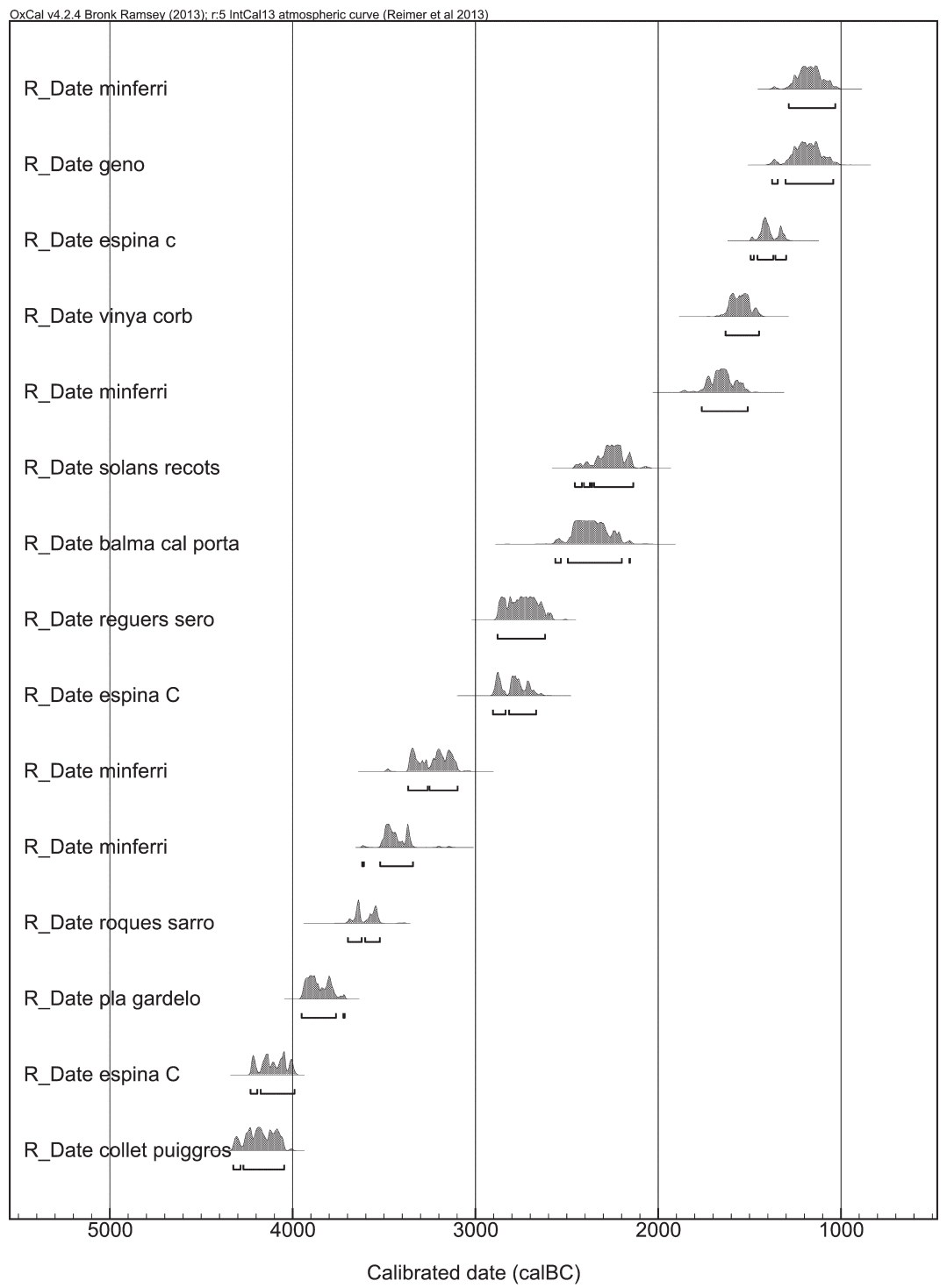

Figura 9. Quadre de les datacions calibrades de jaciments de l'àrea d'estudi.

\begin{tabular}{|c|c|c|c|c|c|c|c|}
\hline Jaciment & Municipi & Context & $\begin{array}{c}\text { Tipus } \\
\text { mostra }\end{array}$ & $\begin{array}{c}\text { Codi } \\
\text { laboratori }\end{array}$ & \begin{tabular}{|c|} 
Valor \\
BP \\
\end{tabular} & \begin{tabular}{|c|}
$\begin{array}{c}\text { Desvia- } \\
\text { ció }\end{array}$ \\
\end{tabular} & Bibliografia \\
\hline Minferri & Juneda, Garrigues & Sitja 296 & Os humà & Beta 181658 & 2960 & 40 & http://www.telearchaeology.com \\
\hline Genó & Aitona, Segrià & Habitació 2 & Carbó & GrN18061 & 2970 & 45 & Maya et al. 1998 \\
\hline Espina $\mathrm{C}$ & Tàrrega, Urgell & Sitja 27 & Os fauna & Beta-385145 & 3130 & 30 & Piera 2014 \\
\hline Vinya Corb & Basella, Alt Urgell & \begin{tabular}{|l|} 
Estructura \\
funerària E-2
\end{tabular} & Os humà & Beta-257040 & 3270 & 40 & Inèdita \\
\hline Minferri & Juneda, Garrigues & Sitja 296 & Os humà & Beta 181657 & 3360 & 50 & http://www.telearchaeology.com \\
\hline Solans Recots & Nalec, Urgell & Balma sepulcral & Os humà & UBAR 1025 & 3810 & 40 & Armentano et al. 2010 \\
\hline $\begin{array}{l}\text { Balma Cal } \\
\text { Porta }\end{array}$ & Torà, Segarra & Balma sepulcral & Os humà & UBAR 297 & 3890 & 60 & Mestres, Martín 1996 \\
\hline Reguers Seró & $\begin{array}{l}\text { Artesa de Segre, } \\
\text { Noguera }\end{array}$ & $\begin{array}{l}\text { Estructura } \\
\text { funerària }\end{array}$ & Os humà & Beta-230406 & 4150 & 40 & López et al. 2010 \\
\hline Espina $\mathrm{C}$ & Tàrrega, Urgell & Sitja 2 & Os fauna & Beta-247384 & 4210 & 40 & Piera et al. 2009 \\
\hline Minferri & Juneda, Garrigues & Sitja 191 & Carbó & Beta-164902 & 4630 & 40 & http://www.telearchaeology.com \\
\hline Roques Sarró & Lleida, Segrià & $\begin{array}{l}\text { Estrat basal } \\
\text { balma }\end{array}$ & \begin{tabular}{|l|} 
Carbó \\
dispers
\end{tabular} & Beta-92208 & 4830 & 40 & Equip Sarró 2000 \\
\hline Pla Gardelo & \begin{tabular}{|l|} 
Juneda, \\
Garrigues
\end{tabular} & $\begin{array}{l}\text { Estructura } \\
\text { funerària }\end{array}$ & Os humà & Beta-318363 & 5040 & 30 & Inèdita \\
\hline Espina $\mathrm{C}$ & Tàrrega, Urgell & Sitja 3 & Os fauna & Beta-385146 & 5270 & 30 & Piera 2014 \\
\hline Collet & $\begin{array}{l}\text { Puiggròs, Garri- } \\
\text { gues }\end{array}$ & $\begin{array}{l}\text { Estructura } \\
\text { funerària E1 }\end{array}$ & Os humà & UBAR-891 & 5345 & 45 & Piera et al. 2008 \\
\hline Collet & $\begin{array}{l}\text { Puiggròs, Garri- } \\
\text { gues }\end{array}$ & \begin{tabular}{|l} 
Estructura \\
Funerària E5
\end{tabular} & Os humà & UBAR-892 & 5480 & 45 & Piera et al. 2008 \\
\hline
\end{tabular}

Figura 10. Taula de datacions radiocarbòniques. 
nivell, fet que indicaria una dinàmica d'amortització a partir d'una única acció, encara que sense poder determinar si aquesta és de curta o llarga durada. Generalment, els seus rebliments són formats per fines argiles que podrien suggerir un rebliment a partir de filtració d'aigua, després de la desaparició de la matèria orgànica. Tanmateix, alguns forats de pal amb abundants útils o restes carbonitzades en el seu interior, fan plantejar si aquests foren dipositats en el moment d'encabir el pal, o bé haguessin accedit quan el pal hagués pogut ser sostret o descompost. Tanmateix, la major part de les estructures presenten més d'un nivell de rebliment, fet que podria indicar una diversitat d'accions en el procés d'amortització. En algunes estructures (E-2, E-9 i E-15) s'observen bossades de cendres netes al fons de la fossa, les quals es troben cobertes per nivells, d'argila amb cendra barrejada, molt més gruixuts. Aquest darrer tipus d'estrat cendrós també es pot localitzar en estrats intermedis (E-28). Tots aquests nivells cendrosos proporcionen petits fragments d'argila cuita. Aquesta associació podria relacionar els fragments d'argila cuita amb processos de combustió, de tal manera que aquests nivells cendrosos podrien ser interpretats com a abocaments provinents de la neteja i manteniment d'estructures de combustió. En altres estructures, com l'E-7 i l'E-13, s'observa la presència d'abundants pedres i útils fracturats, sobretot en la part més inferior de la fossa, que podrien indicar una finalitat expressa de cobriment.

Algunes estructures proporcionen lloses de pedra disposades de manera plana. En l'E-7 i l'E-4 es troben en el fons de la fossa. Aquestes lloses són un element significatiu a l'hora d'interpretar la funcionalitat de les estructures, ja que podrien correspondre a la tapadora. Una vegada l'estructura estava en desús, aquesta hauria caigut o hauria estat dipositada en el seu interior. La presència d'aquest element indicaria una funció primària d'emmagatzematge de l'estructura, tot i l'escassa fondària de l'E-7, per exemple. Per altra banda, l'E-15 disposa d'una llosa de pedra en un rebliment intermedi que fa que esdevingui complex associar-la com a tapadora de la sitja.

Per altra banda, trobem estructures que han proporcionat un gran nombre de fragments ceràmics $i$ d'altres en què aquests són absents. Per exemple, l'E-2 proporciona un gran nombre de vores corresponents a diferents recipients ceràmics. En un altre cas, trobem que l'E-3 presenta diversos fragments ceràmics però corresponents a un mateix vas ceràmic. Precisament, dins l'E-3, es recuperen diverses restes òssies humanes en posició secundària, una d'elles part d'un fèmur amb una perforació antròpica. La presència de restes òssies en posició secundària, dins d'assentaments a l'aire lliure, no és un fet habitual. En altres assentaments de la plana occidental catalana, com el Pla del Gardelo o el Collet, just al costat d'estructures d'emmagatzematge, han aparegut estructures funeràries que podrien evidenciar la compartició d'un mateix espai per ambdues pràctiques. Aquestes, però, eren primàries $i$ els esquelets mantenien la seva connexió anatòmica. Per tant, en el Neolític postcardial, la presència de pràctiques funeràries en aquest tipus d'assentament no seria un fet excepcional, però sí el fet de trobar-les descontextualitzades en posició secundària. La major part d'enterraments es troben en posició primària com a l'Hort d'en Grimau, Pujolet de Moja o la Bòbila Madurell. Tanmateix, en poblats a l'aire lliure del País Valencià, de finals del VI a principis del III mil.lenni, com Costamar o La Vital, es troben abundants restes humanes en posició secundària que han estat interpretades com a resultat d'una manipulació freqüent dels cadàvers (Bernabeu 2010: 52). A Catalunya, al jaciment dels Camps de la Farigola, del període neolític, es trobaren restes d'un cànid juntament amb un crani humà en posició secundària (Casas et al. 2014).

La interpretació de les restes humanes en posició secundària de l'Espina $\mathrm{C}$ així com de tota la dinàmica d'amortització de l'E-3 esdevé complexa. Per una banda, hi ha una clara associació entre les amortitzacions de l'E-3 i l'E-7 pel remuntatge de fragments ceràmics. Però, a més a més, totes dues comparteixen uns rebliments formats per un sediment molt similar i també es dóna la circumstància que, en la part més fonda, apareixen abundants pedres. És per això que ambdues estructures podrien ser amortitzades per una mateixa acció o per accions similars i, per tant, simultània o pròximes en el temps. Per altra banda, la recuperació de fragments ceràmics de grans dimensions que remunten entre ells i que permeten reconstruir bona part d'un gran recipient ceràmic, podria indicar que aquest s'hagués trencat just en un moment previ a l'amortització de la fossa i en un espai pròxim. Aquestes circumstàncies permeten suggerir una dinàmica d'amortització relacionada amb l'abandonament de l'assentament i fi d'ús d'aquestes estructures. D'aquesta manera, podria haver hagut una destrucció intencional dels mitjans de producció o infraestructures que no podien ser traslladats - com les sitges o bé el mateix recipient ceràmic de grans dimensions- a la fi de l'ocupació. En aquest sentit, les restes humanes en posició secundària podrien ser conseqüència d'una activitat de desmuntatge del poblat, amb la destrucció de les estructures i possibles tombes situades a nivell de superfície. En altres jaciments s'ha plantejat la hipòtesi de la reposició, que consisteix en la neteja dels vestigis superficials del poblat i la deposició de restes dins les fosses, amb el resultat de deixar el lloc de manera similar a com estava abans de ser ocupat (Márquez, Jiménez 2010: 452). Altres han suggerit la destrucció dels hàbitats com a part d'un ritual (Sánchez 2010: 181).

\section{Conclusions}

En els últims anys, l'arqueologia preventiva i, concretament, els seguiments arqueològics de projectes urbanístics i de noves infraestructures, han permès la descoberta d'abundants assentaments a l'aire lliure, bona part dels quals acostumen a estar formats per estructures negatives excavades al subsòl. En molts casos, l'aparença d'aquests assentaments sembla simple, ja que no hi ha una estratigrafia complicada $\mathrm{i}$ les estructures són fàcilment identificables quan el terreny geològic queda al descobert. Però, a més a més, el fet que les estructures sovint tendeixen a formar agrupacions i que se situïn en un mateix pla horitzontal, sense gaires desnivells físics, aporta una imatge unitària de tot el conjunt. Aquesta visió porta 
a interpretar el jaciment com un espai de funcionament sincrònic, sobretot si no hi ha superposicions d'estructures. Tanmateix, cada vegada amb més freqüència, s'evidencia que no existeix un vincle entre estructures sinó que llurs funcionaments poden ser independents.

La manca de connexió física entre les estructures excavades al subsòl genera la problemàtica sobre la identificació de quines són les relacions de diacronia i sincronia entre les diferents estructures, així com els marcs temporals de llurs funcionaments i amortitzacions. La problemàtica se centra en la reconstrucció del procés de formació de l'assentament i la seva evolució al llarg del temps. Per fer front a aquesta problemàtica, en el cas de l'Espina $\mathrm{C}$, s'optà per una anàlisi de la distribució, morfologia i dinàmica de rebliment de les estructures que permeté identificar casos de sincronia per associació espacial o bé de diacronia per superposició física. Per altra banda, l'estudi dels materials arqueològics permeté establir relacions de sincronia entre els rebliments de determinades estructures, a través del remuntatge de materials ceràmics, a la vegada que les atribucions formals i decoratives de la ceràmica evidenciaren separacions cronoculturals entre els materials de diferents estructures. Finalment, les datacions absolutes han permès fixar almenys tres períodes d'ocupació diferenciats, cadascun dels quals separats de manera successiva per un espai de temps d'entorn els 1.000 anys.

L'anàlisi global de tots aquests aspectes ha permès detectar discontinuïtats en el procés de formació de l'assentament, amb llargs períodes de desocupació, amb l'existència d'almenys tres assentaments diferenciats dins d'un mateix espai.

La recurrència en l'ocupació d'un mateix espai en moments temporals tan distants, porta a reflexionar sobre quines són les característiques físiques d'ubicació i quin és el motiu de selecció de l'indret. Precisament, el jaciment de l'Espina C es troba en un espai elevat al mig d'una gran planura, proper a un recurs hídric com és el riu Cercavins i amb disponibilitat de terra fèrtil. Aquestes característiques físiques podrien proporcionar certs avantatges per a l'establiment de grups d'economia agrícola i ramadera. A la vegada, la presència d'un mateix tipus d'estructura en cadascuna de les ocupacions i la compartició d'un mateix espai físic, podria indicar unes estratègies de subsistència $i$ econòmiques similars en cadascun dels grups humans que l'ocuparen.

Tot i que la diacronia temporal entre estructures ha estat ben contrastada per les datacions absolutes, és complex determinar en cada moment temporal, l'entitat de cadascuna de les ocupacions humanes.

La primera ocupació, del $\mathrm{V}$ mil.lenni cal $\mathrm{BC}$, es vincula a dues estructures (E-3 i E-7). Les atribucions culturals dels materials arqueològics indica una cronologia relativa del Neolític postcardial en tres estructures (E-3, E-7 i E-13). La presència en el seu interior de bases de molí, pedres polides i indústria de sílex associada a la sega de cereals, juntament amb la troballa d'una tapadora de pedra, podria suggerir per a aquestes estructures una funcionalitat d'emmagatzematge vinculada a la pràctica agrícola. Per altra banda, les restes faunístiques constaten la presència de gossos i d'ovicàprids, i serien indicatives també d'una pràctica ramadera. Aquestes activitats requereixen un cert grau de sedentarització que s'observa amb inversions de capital fix com ara les estructures d'emmagatzematge o el gran recipient ceràmic. Tot $\mathrm{i}$ no trobar cap enterrament, les restes humanes modificades per acció antròpica i en posició secundària podrien suggerir la realització de pràctiques funeràries en l'entorn de l'assentament.

La següent ocupació, en el III mil-lenni cal BC, es vincula a una única estructura (E-2). Es tracta d'un petit assentament d'un grup humà de base econòmica agrícola, si hem de jutjar per la presència de la sitja i els materials recuperats com una base de molí, un fragment de destral, una làmina de sílex fracturada i els diferents recipients ceràmics. Una part del seu rebliment es vincula a residus procedents d'àrees de combustió, probablement d'una zona d'hàbitat, ja que s'ha recuperat fragments d'argila cuita, restes de fauna i un gran nombre de recipients ceràmics.

La darrera ocupació, del II mil.lenni cal BC, es vincula a una única estructura (E-27), tot i que una altra, l'E-11, aporta materials ceràmics afins al període del bronze. Podria correspondre a un petit assentament de base econòmica agrícola, amb un nombre molt reduït de sitges. En els rebliments es recuperaren diversos fragments ceràmics, pedres polides, útils de sílex i restes de fauna. La pràctica agrícola podria ser complementada per la ramaderia, tot i que les restes faunístiques són molt escasses.

Làrea estudiada mostra l'existència d'un baix nombre d'estructures associades a cadascuna de les ocupacions que podria suggerir un model de poblament similar per totes tres fases d'ocupació. Les diverses ocupacions podrien correspondre a una àrea d'emmagatzematge situada molt a prop de l'hàbitat. En aquest sentit, es detectaren varis forats de pal que formarien part d'una cabana, probablement, vinculada amb l'hàbitat i associada a unes poques sitges i cubetes, que permetrien plantejar l'existència d'una petita explotació agrària familiar i autosuficient. Malgrat tot, el conjunt de forats de pal que conformen aquesta cabana, no han aportat prous materials ceràmics per a la seva atribució cronocultural i tampoc s'ha realitzat cap datació radiocarbònica, de tal manera que fins al moment d'estudi actual del jaciment no s'ha pogut vincular, de manera precisa, a cap de les tres ocupacions documentades. El mateix passa amb altres estructures. D'aquesta manera, la reconstrucció del procés de formació del jaciment de l'Espina C no ha estat finalitzat $i$, en un futur, la continuïtat en l'estudi dels materials i estructures arqueològiques i la realització de noves datacions radiocarbòniques, podrien aportar més relacions de diacronia o sincronia entre les estructures.

Marc Piera Teixidó Grup de Recerca Arqueològica a la Mediterrània i al Pròxim Orient (GRAMPO) (2014 SGR1248) UAB C/ Mossèn Serapi Farré, 52, 4-2 Manresa 08242 pieratex@hotmail.com

Rebut: 14-02-2016 Acceptat: 05-04-2016 
Adserias, M., TeIXell, I., Griñó, D. (2003). Intervencions arqueològiques als Molins de la Vila (Montblanc, Conca de Barberà). Tribuna d'Arqueologia, 19992000: 179-192.

Agustí, B., Alcalde, G., Burjachs, F., Buxó, R., Juanmuns, N., Oller, J., Ros, M. T., Rueda, J. M., Toledo, A. (1987). Dinàmica de la utilització de la Cova 120 per l'home en els darrers 6.000 anys. Sèrie Monogràfica, 7. Centre d'Investigacions Arqueològiques de Girona.

Alameda, M. C., Carmona E., Pascual S., Martínez, G., DíEz C. (2011). El “campo de hoyos” calcolítico de Fuente Celada (Burgos): datos preliminares y perspectivas. Complutum, vol. 22 (1): 47-69.

Alcalde, G., Borrell, F., Casellas, S., Molist, M., Oliva, M., Saña, M., Vicente, O. (2005). La Prunera, un assentament del neolític final a l'aire lliure a la zona dels Prepirineus catalans. Tribuna d'Arqueologia, 2001-2002: 39-59.

Alonso, N. (1999). De la llavor a la farina. Els processos agrícoles protohistòrics a la Catalunya occidental. Monographies d'Archéologie Méditerranéenne, 4. Lattes.

Alós, C. (1990). Revisió dels materials arqueològics del Museu Comarcal de la Noguera: el vas neolític del Coll de Porta. La Noguera Estudis, 4: 5-9.

Armentano, N., Gallart, J., Saña, M., Torres, M. (2010). Solans de Recots (Nalec, l'Urgell), una balma d'enterrament collectiu a la vall del Corb. Urtx, 24: 106-137.

Baldellou, V., Mestres, J. (1977). La cova de la Font del Molinot. Una nueva facies neolítica. A: XIV Congreso Nacional de Arqueología. Saragossa: 249-252.

Bellido, A. (1996). Los campos de hoyos. Inicio de la economía agrícola en la submeseta norte. Studia Archaeologica, 85. Universidad de Valladolid.

Bernabeu, J. (2010). El mundo funerario entre el VI y el II milenio A.C. A: Pérez, A., Soler, B. (coord.). Restos de vida, restos de muerte. La muerte en la prehistoria. Museu de Prehistòria de València: 45-54.

Bernabeu, J., Orozco, T., Díez, A., Gómez, M., Molina, J. F. (2003). Mas d'Is (Penàguila, Alicante): aldeas y recintos monumentales del neolítico inicial en el valle del Serpis. Trabajos de Prehistoria, 60, 2: 39-59.

Boquer, S., Bosch, J., Cruells, W., Miret, M., Molist, M., Rodón, T. (1995). El jaciment de l'institut de Batxillerat Antoni Pous. Un assentament a l'aire lliure de finals del calcolitic (Manlleu, Osona). Memòries d'Intervencions Arqueològiques a Catalunya, 15. Generalitat de Catalunya. Barcelona.

Bordas, A., Salazar, N. (2006). Vestigis del neolític final al barri del Raval de Barcelona: estudi de les restes trobades al carrer Reina Amàlia. Quarhis, Època II: 25-35.

Bosch, A., TARrús, J. (1990). La cova sepulcral del neolític antic de l'Avellaner (Cogolls, Les Planes d'Hostoles. La Garrotxa). Centre d'Investigacions Arqueològiques de Girona. Sèrie Monogràfica núm 11. Girona.

Bosch, A., Chinchilla, J., Tarrús, J. (coord.) (2000). El poblat lacustre neolitic de La Draga: excavacions de 1990 a 1998. Monografies del CASC 2. Museu d'Arqueologia de Catalunya.

Bosch, J., Forcadell, A., Villalbí, M. (1996). El Barranc de Fabra: asentamiento de inicios del IV milenio AC en el curso inferior del Ebro. Rubricatum, 1. Actes I Congrés del Neolític a la Península Ibèrica. GavàBellaterra, 1995: 391-396.

Bouso, M. et al. (2004). Anàlisi comparatiu de dos assentaments del bronze inicial a la depressió prelitoral catalana: Can Roqueta II (Sabadell, Vallès Occidental) i Mas d'en Boixos (Pacs del Penedès, Alt Penedès). Cypsela, 15: 73-101.

Carlús, X., López Cachero, F., Terrats, N., Oliva, M., Palomo, A., Rodríguez, A. (2008). Diacronia durant la prehistòria recent a Can Roqueta (Sabadell-Barberà del Vallès, Vallès Occidental) entre el VI i el I mil.lenni cal ANE. Cypsela, 17: 115-142.

Carlús, X., González, J. (2008). Carrer de la Riereta, 37-37 bis: un nou assentament prehistòric al pla de Barcelona. Primers resultats. Cypsela, 17: 91-114.

Carlús, X., De Castro, O. (2014). El Bosc del Quer (Sant Julià de Vilatorta, Osona) un nou establiment del calcolític-bronze a la plana osonenca. Actes II Jornades d'arqueologia de la Catalunya Central. Vic: 20-31.

Carmona, E. (2012). Las comunidades campesinas calcolíticas en el Valle Medio del Arlanzón (cal. 30001900 a.C.): transformaciones y procesos históricos. Tesi doctoral. Universidad de Burgos. <http:/hdl.handle. net/10259/175>.

Casas, J., Martí, M., Gómez, A., Molist, M. (2014). Noves evidències dels primers pagesos consolidats al riu Ter: Camps de la Farigola i Camps de Can Baulenas (Masies de Voltregà). Actes II Jornades d'arqueologia de la Catalunya Central. Vic: 43-52.

Castany, J., Alsina, F., Guerrero, L. (1992). El Collet de Brics d'Ardèvol. Un hàbitat del calcolitic a l'aire lliure (Pinós, Solsonès). Memòries d'Intervencions Arqueològiques a Catalunya, 2. Departament de Cultura. Generalitat de Catalunya.

Castany, J. (1995). Les coves prehistòriques de les Grioteres (Vilanova de Sau, Osona). Sèrie Monografies, 16. Patronat d'Estudis Osonencs. 
Clop, X., Faura, J. M., Gibaja, F. J., Piqué, R. (2005). Els Vilars de Tous (Igualada, Barcelona): una estructura de habitación y producción lítica del V milenio cal BC. Actas del III Congreso del Neolítico en la Península Ibérica: 551-558.

Clop, X., Costafreda, A., Gallart, J., Gibaja, J. F., Llussà, A. (2006a). Els jaciments neolítics de la Torre del Garrell (Lleida, El Segrià). A: Arqueologia $i$ arqueòlegs. Actes de la XXXV Jornada de Treball. Grup de Recerques Terres de Ponent. Verdú 2004. Homenatge a Ramon Boleda Cases: 83-100.

Clop, X., Gallart, J., Gibaja, J. F., Ribes, J. (2006b). Un jaciment del Neolític final-calcolític a Vilanova de Remolins (Torres de Segre, Segrià). A: Arqueologia $i$ arqueòlegs. Actes de la XXXV Jornada de Treball. Grup de Recerques Terres de Ponent. Verdú 2004. Homenatge a Ramon Boleda Cases: 101-115.

Consuegra, S., Díaz-Del-Río, P. (2007). El yacimiento de la Albareja (Fuenlabrada, Madrid): un ejemplo de poblamiento disperso de la primera Edad del Hierro. A: Estudios sobre la Edad del Hierro en la Carpetania. Zona Arqueológica núm 10. Museo Arqueológico Regional. Alcalá de Henares: 133-152.

Delibes, G., Zapatero, P. (1996). De lugar de habitación a sepulcro monumental: una reflexión sobre la trayectoria del yacimiento neolítico de La Velilla, en Osorno (Palencia). Rubricatum 1, vol. 1. I Congrés del neolític a la Península Ibèrica: 337-348.

Díaz-Del-Río, P., Consuegra, S. (1999). Primeras evidencias de estructuras de habitación y almacenaje neolíticas en el entorno de la Campiña madrileña: el yacimiento de "La Deseada" (Rivas-Vaciamadrid, Madrid). II Congrés del Neolitic a la Península Ibèrica. Saguntum-PLAV, Extra-2: 251-257.

Edo, M., Blasco, A., Villalba, M. J. (2011). La cova de Can Sadurní, guió sintètic de la prehistòria recent de Garraf. A: Blasco, A., Edo, M., Villalba, M. J. (coords.). La cova de Can Sadurní $i$ la prehistòria de Garraf. Recull de 30 anys d'investigació. Edar Arqueología y Patrimonio.

Equip Minferri (1997). Noves dades per a la caracterització dels assentaments a l'aire lliure durant la I meitat del II mil.lenni cal. BC: primers resultats de les excavacions en el jaciment de Minferri (Juneda, Les Garrigues). Revista d'Arqueologia de Ponent, 7: 161-211.

Equip SARRó (2000). Les Roques del Sarró (Lleida, Segrià): evolució de l'assentament entre el 3600 cal a.n.e. i el 175 a.n.e. Revista d'Arqueologia de Ponent, 10: $103-176$.

Escala, O., Moya, A., Tartera, E., Vidal, A., ArmentaNo, N. (2014). La Cantorella (Maldà, Urgell), un nou assentament a l'aire lliure del neolític final-calcolític i del bronze ple a la vall del riu Corb. A: ARmentano, N. La reconstrucció tafonòmica dels enterraments col-lectius. Tesi doctoral. Universitat Autònoma de Barcelona.
Departament de Biologia Animal, de Biologia Vegetal i d'Ecologia.

Esteve, X., Martín, P., Oms, F. X., López, D., JorNET, R. (2012). Intervencions arqueològiques als enllaços de l'autopista AP-7 de Vilafranca del Penedès: nous assentaments prehistòrics a l'aire lliure al Penedès. Tribuna d'Arqueologia, 2010-2011: 23-40.

Farré, J., Mestres, J., Senabre, M. R., Feliu, J. M. (2002). El jaciment del Mas d'en Boixos (Pacs del Penedès, Alt Penedès). Un espai utilitzat des del Neolític fins a l'època ibèrica. Tribuna d'Arqueologia, 19981999: 113-134.

Flores, R., Sanabria, P. J. (2012). La Cuesta, Torrejón de Velasco (Madrid) un hábitat singular de la I Edad del Hierro. A: Morín, J., Urbina, D. El Primer milenio AC: en la Meseta Central. De la longhouse al oppidum. AUDEMA. Madrid: 151-171.

FonT, J. (2005). Noves aportacions al neolític finalcalcolític verazià: l'assentament del Camp del Rector (Jorba, Anoia) i les estructures de combustió del sector II de Can Vinyalets (Santa Perpètua de Mogoda, Vallès Occidental. Tribuna d'Arqueologia, 2001-2002: 61-91.

FonT, J. (2006). Les estructures del neolític finalcalcolític i del bronze mitjà-recent de Can Vinyalets (Santa Perpètua de Mogoda). Notes, vol. 21. Monogràfic. El patrimoni arqueològic del Baix Vallès: 185-216.

Fortó, A., Martínez, P., Muñoz, V. (2005). El jaciment arqueològic de Ca l'Estrada (Canovelles). Lauro, 28: 5-28.

Francès, J. (1995). Noves excavacions al sector est del jaciment del poliesportiu de la UAB (Cerdanyola, Vallès Occidental). Revista d'Arqueologia de Ponent, 5: 147-173.

Gallart, J., Ribes, J. (1988). Un jaciment del neolític final a la comarca del Segrià. VIIè Col-loqui internacional d'arqueologia de Puigcerdà. Homenatge a J. Maluquer de Motes, 6-8 de juny de 1986: 59-66.

Gallart, J. Ribes, J. (2001). La balma del Clotar. Un jaciment del neolític final-calcolític a la Vall-llebrera (Artesa de Segre, La Noguera). Urtx, 14: 8-17.

GonZÁLEz, J. (2010). Memòria de l'excavació arqueològica a la Balma d'Ollers (Solivella, Conca de Barberà). Inèdita, lliurada al Servei d'Arqueologia i Paleontologia.

González, P., Martín A., Mora. R. (1999). Can Roqueta. Un establiment pagès prehistòric i medieval (Sabadell, Vallès Occidental). Excavacions Arqueològiques a Catalunya, 16. Generalitat de Catalunya.

GonzÁLEz, P. (2010). El material ceràmic del jaciment de Forat de Conqueta (Santa Linya, Lleida). Treballs d'Arqueologia, 16: 97-105.

Granados, J. O. (1981). Notas sobre el Neolítico en la Cueva de l'Or (Sant Feliu de Llobregat, Barcelona). A: El neolitic a Catalunya. Taula Rodona de Montserrat, 
Maig 1980. Publicacions de l'Abadia de Montserrat: $145-160$

Liesau, C., Blasco, C., Ríos, P., Vega, J., MenduiÑa, R., Blanco, J. F., Baena, J., Herrera, T., Petri, A., Gómez, J. L. (2008). Un espacio compartido por vivos y muertos: El poblado calcolítico de fosos de Camino de las Yeseras (San Fernando de Henares, Madrid). Complutum, vol. 19 (1): 97-120.

Llovera, X., Colomer, A. (1989). La cultura dels sepulcres de fossa. A: Exposició Andorra Arqueològica. Andorra: 35-40.

López, J. B. (2001). Minferri en el context de l'edat del bronze a la plana occidental catalana. A: GIP, Colors de la Terra. Minferri. La vida $i$ la mort en una aldea d'ara fa 4.000 anys. Quaderns de la Sala d'Arqueologia 1. IEI. Lleida: 13-40.

López, J. B., Moya, A., Escala, O., Nieto, A. (2010). La cista tumulària amb esteles esculpides dels Reguers de Seró (Artesa de Segre, Lleida): una aportació insòlita dins de l'art megalític peninsular i europeu. Tribuna d'Arqueologia, 2008-2009: 87-125.

Marcet, R., Morral, J. (1982). El jaciment de les Escoles Nacionals de Santa Perpètua de la Mogoda (Vallès Occidental). Informació Arqueològica, 39: 67-73.

MÁrquez, J. E., Jiménez V. (2010). Recintos de fosos. Geneoalogía y significado de una tradición en la Prehistoria del suroeste de la Península Ibérica (IV-III milenios $A C$ ). Universidad de Málaga.

Martín, A. (1977). El grupo de Veraza en Cataluña. A: XIV Congreso Nacional de Arqueología: 341-356.

Martín, A., Miret, J., Blanch. R. M., Aliaga, S., Enrich, R., Colomer, S., Albizurri, S., Bosch, J. (1988). Campanya d'excavacions arqueològiques 1987-88 al jaciment de la Bòbila Madurell-Can Feu (Sant Quirze del Vallès, Vallès Occidental). Arraona, 3, Època III: 9-23.

Martín, J., Jiménez, M. C. (1988-1989). En torno a una estructura constructiva en un "campo de hoyos" de la Edad del Bronce de la meseta española en Forfoleda (Salamanca). Zephyrus, XLI-XLVII: 263-283.

Maya, J. L., Cuesta, F., López Cachero, J. (1998). Genó: un poblado del bronce final al Bajo Segre (Lleida). Universitat de Barcelona.

Mestres, J. S., Martin, A. (1996). La calibración de las fechas radiocarbónicas y su contribución al estudio del Neolítico catalán. A: Actas del I Congrés del Neolític a la Península Ibèrica. Formació i implantació de les comunitats agrícoles (Gavà-Bellaterra,1995). Rubricatum, 1, vol. II: 791-804.

Mestres, J. (1988-1989). Les sepultures neolítiques de l'Hort d'en Grimau (Castellví de la Marca, Alt Penedès). Olerdulae, XIII-XIV: 97-129.

Mestres, J., Farré, J., Senabre, M. R. (1998). Anàlisi microespacial de les estructures enfonsades del neolític a l'edat del ferro a la plana del Penedès. Cypsela, 12: 11-29.

Misiego, J., Marcos, G. J., Martín, M. A., Sanz, F. J., Villanueva, L. A. (2005). La Guaya (Berrocalejo de Aragona, Ávila): Reconstrucción de la vida y economía de un poblado en los albores de la Edad del Hierro. A: Blanco, A., Cancelo, C., Esparza, A. (eds.). Bronce final y edad del Hierro en la Península Ibérica. Encuentro de Jóvenes Investigadores. Salamanca: 207-228.

Moya, A., López, J. B., Lafuente, A., Rey, J., TarteRa, E., Vidal, A., Equip Vincamet 2005 (2005). El Grup del Segre-Cinca II (1250-950 cal. a.n.e.) a les terres del Baix Cinca: el poblat clos de Vincamet (Fraga, Osca). Revista d'Arqueologia de Ponent, 15: 13-58.

Muñoz, K., Ortega, J. (1997). Elementos de inspiración orientalizante en la cuenca media del río Tajo: el yacimiento de "Puente de Jarama" (Aranjuez, Madrid). SPAL, 6: 141-163.

Palomo, A., Rodríguez A., Carbó, M., Comellas, S. (2002). Estructures d'hàbitat del bronze inicial a Can Roqueta II (Sabadell, Vallès Occidental). A: Pirineus $i$ veïns al 3er Mil.lenni AC. XII Col.loqui Internacional d'Arqueologia de Puigcerdà: 10-12 de novembre de 2000: 227-234.

Petrt, M. A. (1996). El procés de neolitització a la vall del Segre. La cova del Parco (Alòs de Balaguer, La Noguera). Estudi de les ocupacions humanes del Vè al IIn. Mil.lenni a $C$. Monografies del SERP, 1. Barcelona.

Piera, M. (2007). Memòria de la intervenció arqueològica d'urgència a l'Espina C (Tàrrega, Urgell). Inèdita, lliurada al Servei d'Arqueologia i Paleontologia.

Piera, M. (2008). El jaciment de la Vinya del Corb (Bassella, Alt Urgell). 1r Col-loqui d'Arqueologia d'Odèn (Solsonès). La prehistòria avui en el Prepirineu lleidatà. Odèn, 19, 20 i 21 de maig de 2006. Museu Diocesà i Comarcal de Solsona: 23-30.

Piera, M. (2010). El jaciment neolític del Pla del Gardelo (Juneda). A: Cabal de petjades. VII Trobada d'Estudiosos de les Garrigues. Vinaixa, 24 d'octubre de 2009. Editorial Fonoll. Juneda: 59-68.

Piera, M. (2014). Estudi dels materials ceràmics del jaciment de l'Espina C (Tàrrega, l'Urgell). Treball de Fi de Màster inèdit. Universitat Autònoma de Barcelona.

Piera, M., Pla, A., Antolín, F., Alonso, N., Camarós, E., Clop, X., Gibaja, J. F., Saña, M., Gallart, J. (2008). El Collet de Puiggròs. Un assentament a l'aire lliure de l'època neolítica. A: Fites en el Temps VI Trobada d'Estudiosos de les Garrigues. El Cogul, 27 d'octubre de 2007. Editorial Fonoll. Juneda: 23-48.

Piera, M., Antolín, F., Alonso, N., Clop, X., GibaJa, J. F., SaÑa, M., Gallart, J. (2009). La intervenció arqueològica al jaciment del Neolític Final de l'Espina C (Tàrrega, l'Urgell). URTX. Revista Cultural de l'Urgell, 23: 12-49. 
Piera, M., Pancorbo, A., Garcés, I., Gallart, J. (2013). Els assentaments de les edats del bronze, ibèrica i romana dels Llirians del Mas i les Torres (Salàs de Pallars, Pallars Jussà). Revista d'Arqueologia de Ponent, 23: $163-200$.

Pons, E. (1994). L'hàbitat a Catalunya durant el primer mil.leni aC: Els precedents de l'habitació consolidada. Cota Zero, 10: 9-18.

Prats, G. (2013). Aproximació tipològica i funcional de les estructures excavades al jaciment del bronze ple de Minferri (Juneda, les Garrigues): emmagatzematge i conservació a la Catalunya occidental. Revista d'Arqueologia de Ponent, 23: 89-126.

Roig, J., Molina, D., Coll, J. M., Molina, J. A. (2008). El jaciment calcolític del Vapor Gorina (Sabadell, Vallès Occidental). Tribuna d'Arqueologia, 2007. Departament de Cultura de la Generalitat de Catalunya. Barcelona: 93-122.

Romero, V., Miró, J. M. (1993). Un hàbitat neolític a l'entorn de la riera de Maspujols: la Timba del Bareny (Riudoms, Baix Camp). Boletín Arqueológico de Tarragona, 15: 347-355.

Rosillo, R., Tarrús, J., Palomo, A., Bosch, A., García de Consuegra, R. (2010). Les esteles amb banyes de la Serra del Mas Bonet (Vilafant, Alt Empordà) dins de l'art megalític de Catalunya. Cypsela, 18: 43-59.

Rosillo, R., Palomo, A., Tarrús, J., Bosch, A., García, R., Antolín, F., Campeny, G., Clemente, I., Clop, X., García, E., Gibaja, J. F., Oliva, M., Piqué, R., Saña, M., Terrades, X. (2012). Darreres troballes de la prehistòria recent a l'Alt Empordà. Dos assentaments a l'aire lliure: la Serra del Mas Bonet (Vilafant) i els Banys de la Mercè (Capmany). Tribuna d'Arqueologia, 2010-2011: 41-62.

SÁnchez, A. (2010). La muerte en la arqueología: visiones cruzadas/posiciones encontradas. Futuro del Pasado, 1: 173-187.

TARrús, J. (1982). El Neolític Antic a les comarques gironines. A: El neolític a Catalunya. Taula Rodona de
Montserrat, maig 1980. Publicacions de l'Abadia de Montserrat: 33-57.

Tarrús, J., Chinchilla, J. (1985). El jaciment a l'aire lliure del neolític final de Riera de Masarac (Pont de Molins, Alt Empordà). Empúries, 47: 42-69.

Tarrús, J., Chinchilla, J., Mercadal, O., Aliaga, S. (1996). Fases estructurals i cronològiques a l'hàbitat neolític de Ca N'Isach (Palau-Saverdera, Alt Empordà). Rubricatum, 1. Actes I Congrés del neolític a la Península Ibèrica. Gavà-Bellaterra, 1995: 429-438.

Terrats, N. (2010). L'hàbitat a l'aire lliure en el litoral i prelitoral català durant el bronze inicial: anàlisi teòrico-metodològica aplicada a l'assentament de Can Roqueta (Sabadell-Barberà del Vallès, Vallès Occidental). Cypsela, 18: 141-155.

Urbina, D., Morin, J., Ruiz, L. A., Agustí, E., MonteRo, I. (2007). El yacimiento de Las Camas, Villaverde, Madrid Longhouses y elementos orientalizantes al inicio de la Edad del Hierro, en el valle medio del Tajo. Gerión, 25, 1: 45-82.

Urbina, D., Urouijo, C. (2012). El yacimiento de las Lunas, Yuncler (Toledo): una ciudad de cabañas. A: Morín, J., Urbina, D. El Primer milenio AC: en la Meseta Central. De la longhouse al oppidum. AUDEMA. Madrid: 175-194.

Valiente Malla, J. (1984). Pico Buitre (Espinosa de Henares, Guadalajara): la transición del Bronce al Hierro en el Alto Henares. Wad-al-Hayara, 11: 9-58.

Villalba, M. J., Bañolas, L., Arenas, J., Alonso, M. (1986). Les mines neolitiques de Can Tintorer (Gavà). Excavacions 1978-1980. Excavacions Arqueològiques a Catalunya, núm. 6. Departament de Cultura de la Generalitat de Catalunya.

Villanueva, L., Carmona, E., Arnaiz, M. A., Delgado, M. E. (2012). La articulación del espacio en el "Campo de Hoyos" de Manantial de Peñuelas (Celada del Camino, Burgos). Actas de las segundas jornadas de jóvenes investigadores del valle del Duero, 109-127. 